\title{
Evaluating Light Availability, Seagrass Biomass, and Productivity Using Hyperspectral Airborne Remote Sensing in Saint Joseph's Bay, Florida
}

\author{
Victoria J. Hill • Richard C. Zimmerman • \\ W. Paul Bissett • Heidi Dierssen • David D. R. Kohler
}

Received: 29 October 2012 / Revised: 23 December 2013 / Accepted: 26 December 2013

(C) Coastal and Estuarine Research Federation 2014

\begin{abstract}
Seagrasses provide a number of critical ecosystem services, including habitat for numerous species, sediment stabilization, and shoreline protection. Ariel photography is a useful tool to estimate the areal extent of seagrasses, but recent innovations in radiometrically calibrated sensors and algorithm development have allowed identification of benthic types and retrieval of absolute density. This study demonstrates the quantitative ability of a high spatial resolution $(1 \mathrm{~m})$ airborne hyperspectral sensor (3.2 nm bandwidth) in the complex coastal waters of Saint Joseph's Bay (SJB). Several benthic types were distinguished, including submerged and floating aquatic vegetation, benthic red algae, bare sand, and optically deep water. A total of $23.6 \mathrm{~km}^{2}$ of benthic vegetation was detected, indicating no dramatic change in vegetation area over the past 30 years. SJB supported high seagrass density at depths shallower than $2 \mathrm{~m}$ with an average leaf area index of $2.0 \pm 0.6 \mathrm{~m}^{2} \mathrm{~m}^{-2}$. Annual seagrass production in the bay was $13,570 \mathrm{t} \mathrm{C}$ year $^{-1}$ and represented $41 \%$ of total marine primary production. The effects of coarser spatial resolution were investigated and found to
\end{abstract}

Communicated by Wayne S. Gardner

V. J. Hill $(\bowtie) \cdot$ R. C. Zimmerman

Department Ocean, Earth and Atmospheric Sciences, Old Dominion

University, 4600 Elkhorn Avenue, Norfolk, VA 23529, USA

e-mail: vhill@odu.edu

W. P. Bissett • D. D. R. Kohler

Florida Environmental Research Institute, 10500 University Drive,

Suite 140, Tampa, FL 33612, USA

H. Dierssen

Marine Sciences/Geography, Department of Marine Sciences,

University of Connecticut, 1080 Shennecossett Road,

Groton, CT 06340, USA

Present Address:

W. P. Bissett • D. D. R. Kohler

WeoGeo, Inc., 2828 SW Corbett Ave., Suite 206,

Portland, OR 97201, USA reduce biomass retrievals, underestimate productivity, and alter patch size statistics. Although data requirements for this approach are considerable, water column optical modeling may reduce the in situ requirements and facilitate the transition of this technique to routine monitoring efforts. The ability to quantify not just areal extent but also productivity of a seagrass meadow in optically complex coastal waters can provide information on the capacity of these environments to support marine food webs.

Keywords Remote sensing · Seagrass · Hyperspectral · Spatial patterns $\cdot$ Submarine landscape

\section{Introduction}

Seagrasses form extensive meadows in shallow coastal environments, where they provide a number of critical ecosystem services, including a source of organic carbon, habitat for numerous species of fish and invertebrates, sediment stabilization, and shoreline protection (Gillanders 2006; Marbá et al. 2006). Despite the environmental and economic significance of these "ecosystem engineers," seagrass populations are threatened worldwide by coastal development and anthropogenic eutrophication and may be nearing a crisis with respect to global sustainability (Short and Wyllie-Echeverria 1996; Orth et al. 2006; Waycott et al. 2009). The overall health of the seagrass system is driven by recruitment, mortality, and abiotic factors, such as light, mechanical disturbance, and nutrients. These biotic and abiotic factors combine to control the spatial distribution and density of seagrass across the submarine landscape (Marba and Duarte 1995; Rose et al. 1999; Orth et al. 2000; Robbins and Bell 2000; Harwell and Orth 2001). In turn, the mosaic nature of the seagrass meadows, including the degree of patchiness, gap dynamics, habitat edge type, and connectivity, controls animal recruitment and movement among patches (Kurdziel and Bell 1992; With and Crist 
1995; Hovel and Lipcius 2001; Bell et al. 2006). The continued study of landscape dynamics as they apply to both the health of the seagrass meadows and the animals they support depends on accurate, fine-scale, and quantitative measurements of areal coverage and seagrass density. Through metrics such as seagrass density and primary production, we can provide a direct relationship to population dynamics of juvenile and adult invertebrate species (Warren et al. 2010; Ralph et al. 2013) and biogeochemical properties such as release of labile dissolved organic carbon (Moriarty et al. 1986) and removal or burial of particulate carbon (Mateo et al. 2006).

Remote sensing by aircraft or satellite has proven to be useful at providing spatial information over large coastal areas (Robbins 1997; Dekker et al. 2006; Ferwerda et al. 2007). The spectral reflectance of seagrass leaves provides a marked contrast to the surrounding unvegetated environments (Fyfe 2003; Louchard et al. 2003; Zimmerman 2003; Thorhaug et al. 2007), and submerged aquatic vegetation (SAV) is easily differentiated from bright sand. These spectral characteristics are distorted by the overlying water column, so that the remotely sensed reflectance is derived from a combination of benthic reflectance and the optical properties of the water column itself (Lee et al. 1999). Changes in the quantity of phytoplankton biomass, suspended sediment, or colored dissolved organic material within the water column affect the optical properties overlying the seabed (Dierssen et al. 2003; Han and Rundquist 2003; Vahtmae et al. 2006; Silva et al. 2008) shifting the spectral characteristics of sea surface reflectance.

Radiometrically uncalibrated aerial photography is used with considerable success to map the relative abundance (e.g., percent cover) of SAV in shallow coastal environments (Kendrick et al. 2000; Meehan et al. 2005; http://web.vims.edu/bio/sav/ index.html). However, the lack of radiometric calibration generally precludes accurate retrieval of absolute density from the imagery. Further, the comparison of uncalibrated imagery across time and space can also be problematic, as differences in solar illumination and water column optical properties will distort the reflectance signal emanating from the submerged vegetation (Dierssen et al. 2003).

Radiometrically calibrated sensors provide precise estimates of target radiance in absolute physical units (e.g., watts per square meter per steradian) that can be used to account for differences in illumination within and among images, allowing for more reliable comparisons across time and space. They also permit the application of radiative transfer theory for retrieval of target optical properties and constituent concentrations that permit more quantitative approaches for mapping benthic environments in optically shallow coastal waters (e.g., Maritorena et al. 1994; Dierssen et al. 2003; Klonowski et al. 2007; Phinn et al. 2008; Pu et al. 2012). Examples of radiometrically calibrated instruments include multispectral sensors, such as SeaWiFS, MODIS, and WorldView2, that provide information from a few $(<10)$ discrete wave bands 25 to $50 \mathrm{~nm}$ in width across the visible spectrum (400 to $700 \mathrm{~nm}$ ), often with gaps between the bands. Radiometrically calibrated hyperspectral sensors, such as AVIRIS, PHILLS, SAMSON, and HICO, provide higher spectral resolution (15 $\mathrm{nm}$ or less) and continuous wavelength coverage across the visible spectrum, allowing for the discrimination of subtle spectral characteristics.

There are several techniques for processing remotely sensed imagery to SAV maps. Supervised thematic classification provides a computationally inexpensive technique based on the similarity of spectral characteristics among picture elements (pixels) within a scene. These similarities may vary across time and space due to changes in solar illumination and water column optical characteristics, requiring expert local knowledge to match pixel characteristics to bottom types for each successive image (Mumby et al. 1997; Mumby and Edwards 2002; Pasqualini et al. 2005; Matarrese et al. 2008). Physics-based methods that use radiative transfer theory (modeling light absorption and scattering) attempt to incorporate the effects of water depth and water column transparency and promise greater generality and accuracy, but they require radiometrically calibrated datasets (Dekker et al. 2011). Continued advances in computational speed and memory capacity have dramatically reduced the practical limitations associated with radiative transfer methods that simultaneously derive water depth, water column constituents, and benthic type (Lee et al. 2001; Mobley et al. 2005; Brando et al. 2009; Sagawaa et al. 2010; Yangab et al. 2010). The application of individual algorithms to the imagery is dependent on study site complexity and access to in situ data; knowledge or retrieval of bathymetry is considered critical in these methods (Dekker et al. 2011). Despite potentially demanding requirements, the retrieval of benthic reflectance and vegetation type from these radiative transfer-based algorithms provides a pathway for the automated determination of density (leaf area index) biomass (in grams per square meter) and the subsequent computation of net primary productivity without the intervention of human experts required for supervised classification (Dierssen et al. 2003; Pu et al. 2012).

The goals of this work were to (a) test bio-optical methods for the retrieval of absolute seagrass abundance in optically complex coastal waters, using methods pioneered in extremely clear tropical waters of the Bahamas Banks (Dierssen et al. 2003; Dierssen et al. 2010); (b) to estimate the contribution of SAV to overall productivity of the Saint Joseph's Bay (SJB) ecosystem; and (c) to explore the importance of spatial resolution in the accurate retrieval of seagrass density and abundance across the submarine landscape.

\section{Methods}

This analysis included in situ field work and imagery collected from an airborne hyperspectral sensor. Image processing steps 
are shown in Fig. 1. All symbols and definitions are summarized in Table 1.

\section{Study Site}

SJB, located on the Florida panhandle in the northern Gulf of Mexico $\left(29.797^{\circ} \mathrm{N}, 85.353^{\circ} \mathrm{W}\right)$, contains dense seagrass meadows in optically complex waters (absorption and scattering are high) that provide an important test for the radiative transfer algorithms that have previously been used in clear waters. Seagrasses form dense meadows dominated by turtlegrass (Thalassia testudinum) in the shallow fringes along the shore $($ depth $<2 \mathrm{~m}$ ) with shoalgrass (Halodule wrightii), manateegrass (Syringodium filiforme), widgeongrass (Ruppia maritima), and stargrass (Halophila engelmannii) also present at lower densities (Wetherell 1997). Since 1938, bay waters have been heavily influenced by suspended sediment and colored dissolved organic material from the Intracoastal Waterway (Stewart and Gorsline 1962). The fine sediments can be resuspended throughout the bay by large storms that frequent the area, resulting in occasional periods of extreme light attenuation (Buonassissi and Dierssen 2010).

\section{Airborne Remote Sensing}

The images used in this study were collected using the Spectroscopic Aerial Mapping System with On-board Navigation (SAMSON) hyperspectral imager (band width $3.2 \mathrm{~nm}, 156$ channels between 400 and $900 \mathrm{~nm}$ ), on 29th and 30th September 2006 (Fig. 2). Ninety-one flight lines were flown over 2 days with a total of approximately $6.5 \mathrm{~h}$ flying time on station (http://web.flenvironmental.org/data flightlogs_index.html\#florida). Pixel resolution of this system was $1 \times 1 \mathrm{~m}$. The hyperspectral imaging (HSI) subsystem was based on an Offner spectrograph design mounted to a push broom imaging CCD camera, specifically designed for the marine environment (Davis et al. 2002; Bissett et al. 2004; Kohler et al. 2004; Bissett et al. 2005). Sensor calibration and deployment schemes were optimized to retrieve precise estimates of upwelling photon densities from dark targets such as water and submerged vegetation, defined here as targets with $<3 \%$ total reflectance. A Multispectral Imagery (MSI) sensor (Trimble Applanix Digital Sensor System 322) and a precision 200-Hz direct geo-reference system (Trimble Applanix 410 Position and Orientation Systems for Aviation) were used to geo-locate the HSI data to within a 1-pixel spatial error (Kohler et al. 2006). Geo-location of each pixel was achieved by "boresighting" the HSI sensor relative to the MSI data over a spatial calibration range and then applying these boresight parameters to each frame of HSI data. The boresight parameters were derived using (1) sensor-measured pointing angles for each CCD pixel, (2) measuring the relative angles between

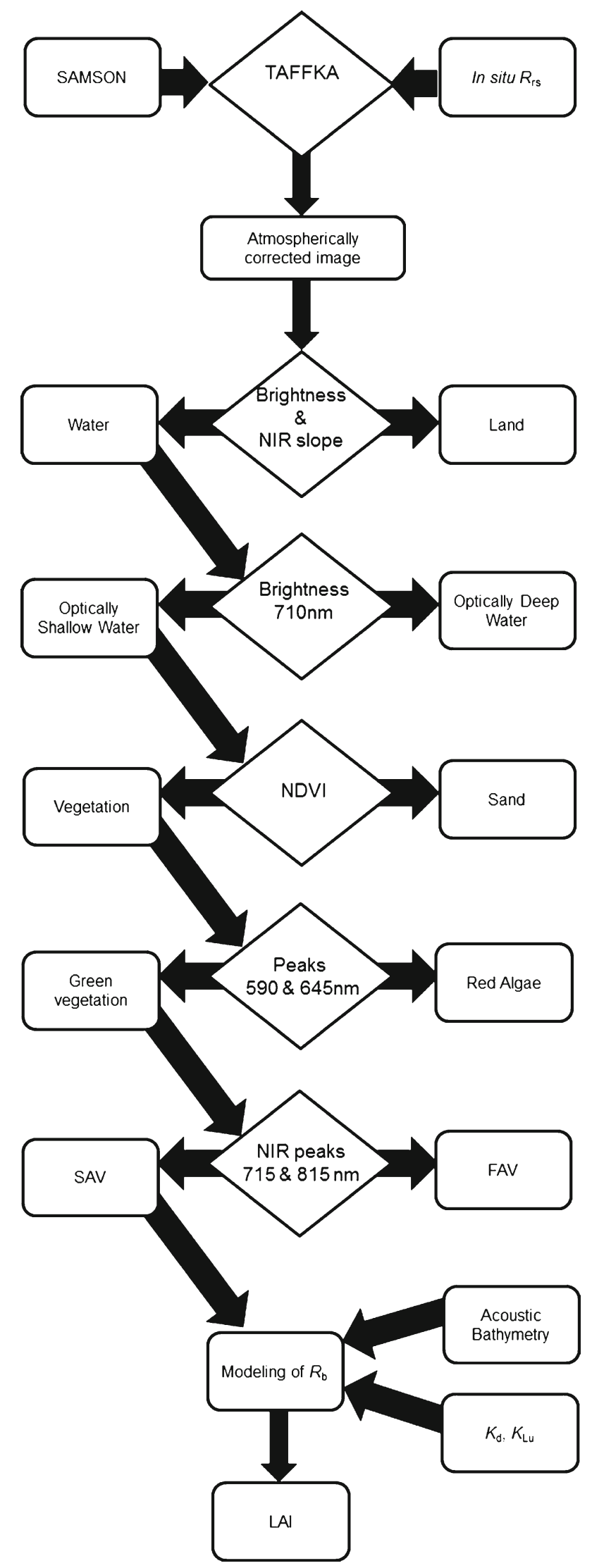

Fig. 1 Flow chart detailing image processing steps 
Table 1 Summary of symbols, their definitions, and dimensions

\begin{tabular}{|c|c|c|}
\hline Symbol & Definition & Dimensions \\
\hline \multicolumn{3}{|c|}{ Basic parameters } \\
\hline$z_{\mathrm{b}}$ & $\begin{array}{l}\text { Depth of the water column from the digital elevation map } \\
\text { corrected for canopy height and tidal state }\end{array}$ & $\mathrm{m}$ \\
\hline TSM & Total suspended material & $\mathrm{mg} \mathrm{m}^{-3}$ \\
\hline LAI & Leaf area index & $\mathrm{m}^{2} \mathrm{~m}^{-2}$ \\
\hline Chl $a$ & Chlorophyll $a$ concentration & $\mathrm{mg} \mathrm{m}^{-3}$ \\
\hline SAV & Submerged aquatic vegetation & $\mathrm{km}^{-2}$ \\
\hline FAV & Floating aquatic vegetation & $\mathrm{km}^{-2}$ \\
\hline MLLW & Mean low lower water & $\mathrm{m}$ \\
\hline CDOM & Colored dissolved organic material & Dimensionless \\
\hline \multicolumn{3}{|c|}{ Inherent optical properties of the water column } \\
\hline$a_{\mathrm{p}}$ & Absorption by particulate material (algal + sediment + detritus) & $\mathrm{m}^{-1}$ \\
\hline$a_{\mathrm{a}}$ & Absorption by algal material & $\mathrm{m}^{-1}$ \\
\hline$a_{\mathrm{n}}$ & Absorption by non-pigmented particulate material & $\mathrm{m}^{-1}$ \\
\hline$a_{\mathrm{g}}$ & Absorption by CDOM & $\mathrm{m}^{-1}$ \\
\hline$a_{\mathrm{pg}}$ & Absorption coefficient by particulate and CDOM measured by the $a c-9$ & $\mathrm{~m}^{-1}$ \\
\hline$c_{\mathrm{pg}}$ & Beam attenuation coefficient measured by the $a c-9$ & $\mathrm{~m}^{-1}$ \\
\hline$b$ & Scattering coefficient measured by the $a c-9$ & $\mathrm{~m}^{-1}$ \\
\hline \multicolumn{3}{|c|}{ Apparent optical properties of the water column } \\
\hline$K_{\mathrm{d}}$ & Spectral diffuse water column attenuation coefficient & $\mathrm{m}^{-1}$ \\
\hline$R_{\mathrm{rs}}$ & Remote sensing reflectance & $\mathrm{sr}^{-1}$ \\
\hline$R_{\mathrm{b}}$ & Benthic reflectance & Dimensionless \\
\hline
\end{tabular}

the sensor and the aircraft GPS, (3) collecting the instantaneous inertial navigation data, (4) correcting the aircraft GPS navigation stream by fixed ground-based station data, and (5) ground control points from a boresight range of known targets.

Optimal angles for light penetration into the water column were considered during flight planning. These encompassed sun elevation from $38^{\circ}$ to $53^{\circ}$ above the horizon and relative azimuth angle between the flight line and the sun of either $0^{\circ}$ or $180^{\circ}$, while minimizing the direct solar reflection from the water (i.e., sun glint) into the field of view of the HSI sensor. Flight lines required to optimize sensor performance were determined immediately prior to each flight and allowed for adjustments due to weather conditions.

\section{Image Processing}

SAMSON-measured radiances were calibrated to absolute units of watts per square meter per nanometer per steradian using NIST-traceable calibration standards (Kohler et al. 2004). The calibration procedures accounted for keystone, smile, and stray light effects of the spectrograph and image smearing effects of the CCD camera. These calibrated, orthorectified HSI radiance data may be downloaded from the FERI data distribution server (http://www.weogeo.com/; FLDEP).

\section{Processing Imagery to Sea Surface Reflectance}

The imagery was further processed to spectral remote sensing reflectance $\left[R_{\mathrm{rs}}(\lambda)\right]$ by correcting for atmospheric and illumination effects, based on the TAFKAA model (Fig. 1; Gao et al. 2000, 2004). The TAFKAA tables are pre-calculated for a variety of scattering aerosols and atmospheric parameters, including aerosol optical depth, aerosol type, water column vapor, ozone, relative humidity, tau (550), and wind speed. The use of TAFKAA in the processing of this data required each ground-based $R_{\mathrm{rs}}(\lambda)$ measured at the water surface to be matched against one of over 75 million solutions to find the set of atmospheric parameters that best corrected the airborne radiances to ground-based observations made at the same geographic point during the flight collections. This best set of atmospheric parameters was then used with the sensor pointing and solar angle geometries taken directly from the Applanix 410 time stamp and positional information and used to correct every pixel in the flight line from sensor radiance to $R_{\mathrm{rs}}(\lambda)$. This manner of atmospheric and illumination correction assumed that the atmospheric conditions did not change during an individual flight window. The $R_{\mathrm{rs}}(\lambda)$ images from 
Fig. 2 RGB image of the Saint Joseph's Bay study region, composited from 91 SAMSON hyperspectral flight lines collected in September 2006. Inset shows the bay's location in the Florida panhandle (USA Topo Map from ArcGIS server).

Stations where benthic and water column measurements were made are identified and numbered (reference Table 2). Benthic stations are those visited in June 2006 where seagrass counts were conducted. Water stations are those visited in September 2006 for sea truthing under the Samson flight lines

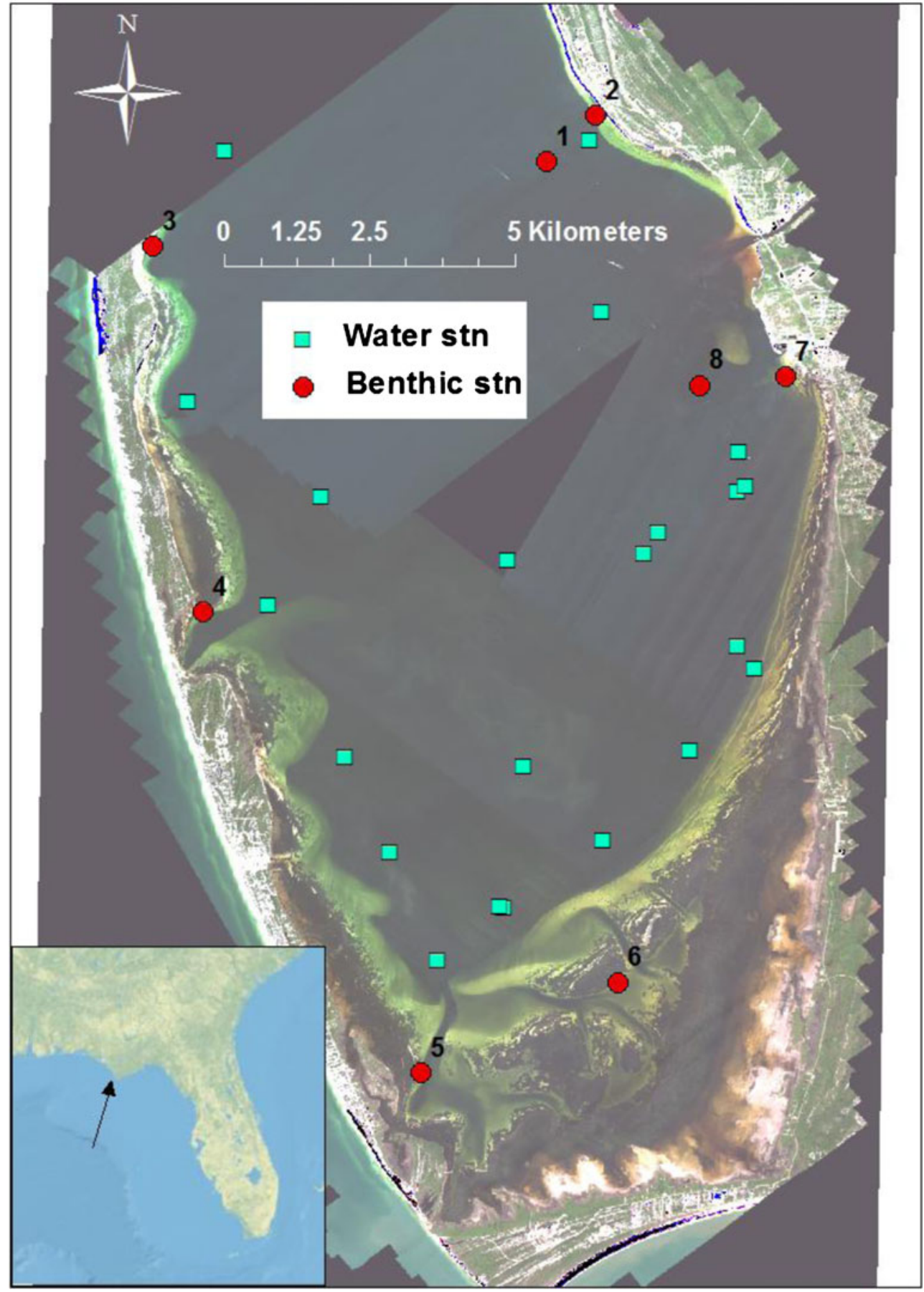

this collection may also be obtained from the FERI data distribution server (http://www.weogeo.com/; FLDEP).

The atmospherically corrected $R_{\mathrm{rs}}(\lambda)$ were smoothed using a running boxcar with a seven-point frequency (approximately $15 \mathrm{~nm}$ ) implemented in ENVI (Ver 4.8, ITTVS), which removed the high-frequency noise without compromising the major spectral characteristics $(30-50 \mathrm{~nm}$ wide) emanating from the targets. To facilitate comparison between the in situ and SAMSON data, the smoothed imagery spectra were resampled to $5 \mathrm{~nm}$ intervals using a cubic spline algorithm.
Algorithms for Benthic Targets

Unvegetated land was identified in the imagery as any pixel with $R_{\mathrm{rs}}(825 \mathrm{~nm}) \geq 0.2 \mathrm{sr}^{-1} \mathrm{~nm}^{-1}$ (Fig. 1). Pixels composed of terrestrial vegetation were identified by a positive NIR slope in $R_{\mathrm{rs}}$ between 725 and $815 \mathrm{~nm}$ (Fig. 1).

$\mathrm{NIR}_{\text {slope }}=\frac{\left[R_{\mathrm{rs}}(725)-R_{\mathrm{rs}}(815)\right]}{725-815}$ 
Optically deep water (ODW; in which bottom reflectance does not contribute measurably to $R_{\mathrm{rs}}$ ) was identified as $R_{\mathrm{rs}}(710 \mathrm{~nm})<0.003 \mathrm{sr}^{-1} \mathrm{~nm}^{-1}$ (Fig. 1). Vegetated marine targets were classified using the red edge of submerged and floating vegetation through the calculation of a Normalized Difference Vegetative Index (NDVI; Fig. 1):

$\mathrm{NDVI}=\frac{R_{\mathrm{rs}}(700)-R_{\mathrm{rs}}(670)}{R_{\mathrm{rs}}(700)+R_{\mathrm{rs}}(670)}$

The presence of two reflectance peaks at 590 and 645 was used to identify red benthic algae (Fig. 1). Band ratios between reflectance peaks at 715 and $815 \mathrm{~nm}$ were used to identify SAV and floating aquatic vegetation (FAV; Fig. 1). A classification accuracy matrix was constructed by comparing the benthic type at each field station with those retrieved from the SAMSON analysis.

\section{In Situ Field Sampling}

Stations were occupied during the period 12th to 18th June 2006 (immediately following Tropical Storm Alberto), 28th September to 1 st October 2006, and 1st to 8th November 2010 (Fig. 2; Table 2). Work in June 2006 included identification and quantification of seagrass abundance, measurement of absorption and scattering properties (inherent optical properties, IOPs), and the downwelling and upwelling light field (apparent optical properties, AOPs) of the overlying water column and benthos. These were used to characterize the optical clarity of the water column and to develop relationships between reflectance and bottom type.

In September 2006, contemporaneous in situ measurements of water column IOPs and AOPs were undertaken with an airborne image campaign using SAMSON flown $850 \mathrm{~m}$ above the sea surface. Ground-based measurements of IOPs, AOPs, and remote sensing reflectance $\left(R_{\mathrm{rs}}\right)$ during the airborne campaign were used to provide ground reference for atmospheric correction (Fig. 1) and for modeling of water column optical properties. The bay was revisited in November 2010 to collect bathymetric data (Fig. 1) critical to the modeling of seagrass density and additional measurements of seagrass canopy reflectance $\left(R_{\mathrm{b}}\right)$.

\section{Seagrass Abundance}

Densities of T. testudinum, $H$. wrightii, and S. filiforme were determined by divers making direct counts of all shoots within 20 to 30 randomly located quadrats $\left(0.04 \mathrm{~m}^{2}\right)$ at each station (Fig. 2; Table 2). One shoot of each species present was collected from each quadrat for subsequent morphometric analysis (total leaf length, leaf width, and number of leaves) and determination of leaf area index $(\mathrm{LAI}=1$ - sided leaf area shoot $^{-1} \times$ shoots $\mathrm{m}^{-2}$; Table 2 ).

\section{Water Column Optical Properties}

\section{Inherent Optical Properties}

In situ spectral absorption $\left(a_{\mathrm{pg}}\right)$ and beam attenuation coefficients $\left(c_{\mathrm{pg}}\right)$ for combined phytoplankton, non-algal, and colored dissolved organic material (CDOM) were measured at nine wavelengths $(412,440,488,510,532,555,650,676$, $715 \mathrm{~nm}$ ) using a Wetlabs $a c-9$ instrument deployed at a constant depth at each station $(0.7 \mathrm{~m})$. Data were processed and corrected for ambient temperature, salinity, and scattering by first correcting absorption to zero at $715 \mathrm{~nm}$ and then assuming a wavelength independent scattering phase function in accordance with NASA protocols (Pegau et al. 2002).

Water samples were collected from the surface at each station for subsequent analysis in the laboratory. Particles were collected on Whatman GF/F filter pads (nominal pore size $0.7 \mu \mathrm{m})$, using gentle vacuum filtration $(<10 \mathrm{mmHg})$. Total spectral absorbance $\left(D_{\mathrm{p}}\right)$ was determined on the particulate

Table 2 Average seagrass abundance measurements at all stations occupied during June 2006 field work

\begin{tabular}{|c|c|c|c|c|c|}
\hline Station ID & Date & Water depth (m) & Seagrass species & Shoot density (shoots $\left.\mathrm{m}^{-2}\right)( \pm \mathrm{SE})$ & Leaf area index $\left(\mathrm{m}^{2} \mathrm{~m}^{-2}\right)( \pm \mathrm{SE})$ \\
\hline 01 & June 14, 2006 & 6.4 & Optically deep & 0 & 0 \\
\hline 02 & June 14, 2006 & 1.2 & Thalassia/Syringodium & $1,472(152)$ & $3.23(0.30)$ \\
\hline 03 & June 15, 2006 & 1.7 & Thalassia/Syringodium & $911(127)$ & $3.39(0.40)$ \\
\hline 04 & June 15, 2006 & 1.5 & Thalassia/Syringodium & $504(31)$ & $\mathrm{N} / \mathrm{D}$ \\
\hline 05 & June 16, 2006 & 1.6 & Thalassia/Syringodium & $1,125(261)$ & $1.72(0.37)$ \\
\hline 06 & June 16, 2006 & 1.5 & Thalassia/Syringodium & $579(27)$ & $1.85(0.09)$ \\
\hline 07 & June 17, 2006 & 2.2 & ThalassialHalodule & $5,554(1270)$ & $1.32(0.42)$ \\
\hline 08 & June 17, 2006 & 6.9 & Optically deep & 0 & 0 \\
\hline
\end{tabular}

Shoot density was calculated through direct counts of all shoots within 20 to 30 randomly located quadrats $\left(0.04 \mathrm{~m}^{2}\right)$ at each station. Leaf area index was determined using shoot density and morphometric analysis of shoots collected from counted quadrats (total leaf length, leaf width, and number of leaves). Station IDs correspond to labeled stations in Fig. 2 
fraction using the integrating sphere-filter-pad technique in accordance with NASA protocols (Mitchell et al. 2002). A filter pad moistened with Nanopure ${ }^{\circledR}$ water functioned as a spectrophotometric blank. The spectral absorbance of nonpigmented particles $\left(D_{\mathrm{n}}\right)$ was measured after extracting photosynthetic pigments from filters with cold methanol (Kishino et al. 1985). The filter-pad absorbances $\left[D_{\mathrm{p}}(\lambda), D_{\mathrm{n}}(\lambda)\right]$ were corrected for multiple scattering amplification according to Mitchell et al. (2002) and converted to total particulate $\left[a_{\mathrm{p}}(\lambda)\right]$ and non-pigmented particulate $\left[a_{\mathrm{n}}(\lambda)\right]$ absorption coefficients ( $a=2.303 D \times$ filter pad area/volume filtered). The average absorption from 690 to $700 \mathrm{~nm}$ was then subtracted as a correction for residual non-specific absorption. CDOM was captured into clean quartz glass vials by filtration through $0.2 \mu \mathrm{m}$ polycarbonate filters that had been previously acid-washed and rinsed with Nanopure ${ }^{\circledR}$ deionized water. Absorbance of CDOM was measured in a $10-\mathrm{cm}$ quartz curvette against a Nanopure ${ }^{\circledR}$ deionized water blank and converted to an absorption coefficient $\left[a_{\mathrm{g}}(\lambda)\right.$; Mitchell et al. 2002]. The spectral slope of $a_{\mathrm{g}}$ was calculated by linear regression of the $\log$ transformed data between 400 and $600 \mathrm{~nm}$ (Nelson et al. 2004).

Chlorophyll $a(\mathrm{Chl} a)$ concentration of the particulate material was determined spectrophotometrically after collection onto GF/F filters that were then ground and extracted in $90 \%$ acetone (Mantoura et al. 1997). Total suspended material (TSM) was collected onto pre-weighed Whatman Nuclepore Track-Etch ${ }^{\circledR}$ Membrane filters (nominal pore size $0.8 \mu \mathrm{m}$ ) under gentle vacuum and rinsed with deionized water to remove residual salts. The filters were dried at $60{ }^{\circ} \mathrm{C}$ for approximately 5 days and weighed to a precision of $10 \mu \mathrm{g}$. The mass of each TSM sample was calculated by subtracting the pre-sampling weight from the total post-sampling mass. The concentration of TSM (milligrams per liter) was calculated as the ratio of sample mass to volume filtered.

\section{Apparent Optical Properties Measured at the Sea Surface}

Two floating spectroradiometer systems were utilized in tandem to measure downwelling spectral irradiance $\left[E_{\mathrm{s}}\left(0^{+}\right)\right]$ above the sea surface (395 to $795 \mathrm{~nm}, \sim 3.3 \mathrm{~nm}$ bandwidth), upwelling spectral radiance $0.6 \mathrm{~m}$ beneath the sea surface [ $L_{\mathrm{u}}(0.6)$, HTSRB, Satlantic Instr.], and upwelling radiance $0.2 \mathrm{~m}$ beneath the sea surface $\left[E_{\mathrm{u}}(0.2), L_{\mathrm{u}}(0.2)\right.$, respectively, HyperPro, Satlantic Instr.]. Spectral data from these sensors were interpolated to $1 \mathrm{~nm}$ spectral resolution. The upwelling diffuse attenuation coefficient $\left(K_{L_{\mathrm{u}}}\right)$ was calculated from $L_{\mathrm{u}}(0.6 \mathrm{~m})$ and $L_{\mathrm{u}}(0.2 \mathrm{~m})$

$K_{L_{\mathrm{u}}}=-\frac{1}{z} \ln \frac{L_{\mathrm{u}}(0.6)}{L_{\mathrm{u}}(0.2)}$

where $z$ was the difference in depth between the sensors placed at 0.6 and $0.2 \mathrm{~m}(=0.4 \mathrm{~m})$.
Upwelling radiance just beneath the air-water interface $\left[L_{\mathrm{u}}\left(0^{-}\right)\right]$was calculated by propagating $L_{\mathrm{u}}(0.2)$ to the surface using $K_{L_{\mathrm{u}}}$ and Beers law (Kirk 1994). The water leaving radiance above the sea surface $\left[L_{\mathrm{w}}\left(0^{+}, \lambda\right)\right]$ was assumed to be $0.54 L_{\mathrm{u}}\left(0^{-}\right)$(Morel and Mueller 2003). Remote sensing reflectance $\left[R_{\mathrm{rs}}(\lambda)\right]$ was then computed as

$R_{\mathrm{rs}}(\lambda)=\frac{L_{\mathrm{W}}\left(0^{+}, \lambda\right)}{E_{\mathrm{s}}\left(0^{+}, \lambda\right)}$

$K_{L_{\mathrm{u}}}$ and $R_{\mathrm{rs}}$ were determined over unvegetated sand, SAV, and ODW.

\section{Apparent Optical Properties Measured at the Seabed}

Bottom reflectance spectra $\left(R_{\mathrm{b}}\right)$ of benthic types were measured using the Diver-Operated Benthic Bio-optical Spectrometer (DOBBS) in June 2006. The DOBBS (HydroRad-3; HOBI Labs) consists of three plane irradiance sensors which measure upwelling $\left[E_{\mathrm{u}}\right]$ and downwelling $\left[E_{\mathrm{d}}\right]$ irradiances near the seafloor. Two sensors were co-located on a wand to measure $E_{\mathrm{d}}$ and $E_{\mathrm{u}}$, just above the target. $R_{\mathrm{b}}$ was calculated by $E_{\mathrm{d}} / E_{\mathrm{u}}$. The third sensor was placed in an $E_{\mathrm{d}}$ configuration $1 \mathrm{~m}$ above the wand enabling the calculation of $K_{\mathrm{d}}$. Up to six readings were collected over unvegetated sand and seagrass of varying densities at each station. Spectra (nominally $0.3 \mathrm{~nm}$ resolution) were interpolated to $1 \mathrm{~nm}$ with a cubic spline and smoothed using a 21-nm running average.

\section{Bathymetry}

An acoustic bathymetric survey was performed in November 2010 using boats provided by the Florida Department of Environmental Protection. One boat was equipped with a Garmin GPS chart plotter/depth sounder. The other boat was equipped with a Humminbird GPS chart plotter/multibeam sonar. Each sounding was stamped with time and position from the GPS/chart plotter and corrected to mean low lower water (MLLW) by removing tidal effects using NOAA benchmark sheets and predicted tides for SJB (http://tidesandcurrents.noaa. gov). Soundings were also corrected for deployment depth of each transducer below the sea surface $(\sim 10 \mathrm{~cm})$.

A digital elevation model (DEM) of the study area was generated from the corrected soundings using an inverse distance weighting contouring procedure implemented in ArcGIS (Fig. 3). Shoreline position was taken from National Wetlands Inventory, with an elevation defined as $1.0 \mathrm{~m}$ above the 0 (MLLW) datum. Although the resulting DEM is generally accurate, the interpolation routine did not resolve bathymetry in some of the channels in the highly complex lower bay. However, this did not influence the retrievals of bottom type or seagrass density, as the channels were generally too deep to support seagrass. 
Fig. 3 Digital elevation model of Saint Joseph's Bay (MLLW) calculated from acoustic sounding tracks collected in November 2010 (shown as points) using an inverse distance weighting interpolation procedure. Acoustic data were corrected to mean low lower water removing tidal effects NOAA benchmark sheets and predicted tides for SJB (http:// tidesandcurrents.noaa.gov)

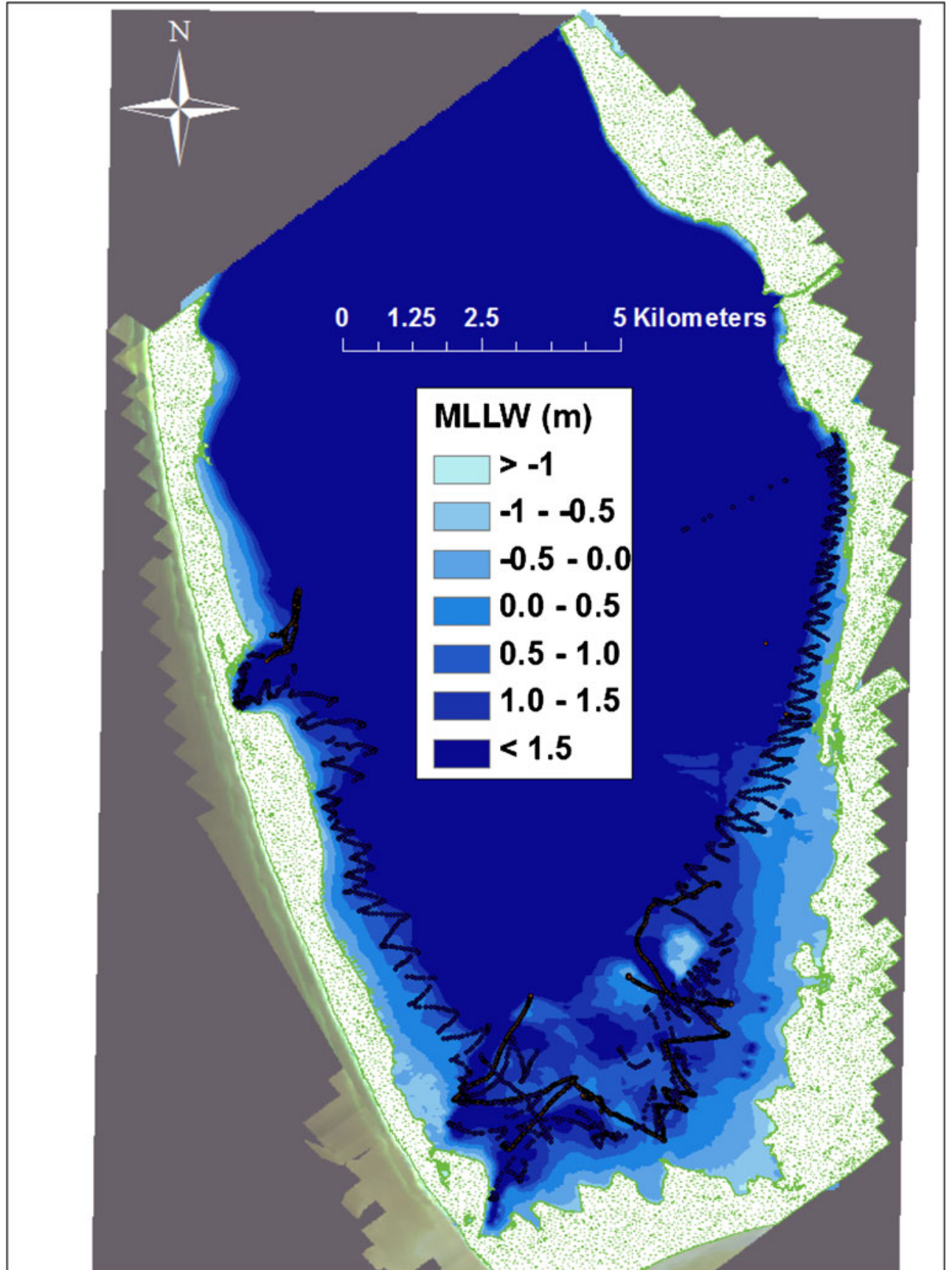

True water depth of each pixel in the hyperspectral imagery was calculated by applying local tide height prediction for the time of acquisition to the MLLW referenced DEM. The full hyperspectral image of SJB was created from a mosaic of several flight lines, and the resulting tidal corrections ranged from 0 to $+0.37 \mathrm{~m}$.

Modeling Bottom Reflectance $\left(R_{\mathrm{b}}\right)$

Quantitative retrieval of seagrass density necessitates removal of the distorting effects of the overlying water column from $R_{\mathrm{rs}}$
(Lee et al. 1994; Maritorena et al. 1994; Dierssen et al. 2003). Here we selected an approach that was previously tested against seagrass growing in white carbonate sand on the clear waters of the Great Bahama Bank (Dierssen et al. 2003):

$R_{\mathrm{b}}=\frac{R_{\mathrm{rs}} \times Q_{\mathrm{b}}}{t} \times \frac{\exp \left[\begin{array}{l}-\overline{K_{L_{\mathrm{u}}}\left(z_{\mathrm{b}}\right)} \times z_{\mathrm{b}}\end{array}\right]}{\exp \left(-K_{\mathrm{d}} \times z_{\mathrm{b}}\right)}$

where $Q_{\mathrm{b}}$ represented the ratio of $E_{\mathrm{u}}$ to $L_{\mathrm{u}}$ at the base of the water column produced by reflectance of $E_{\mathrm{d}}$ from 
the sea floor and estimated to be $\pi$ for a lambertian (isotropic) surface and $z_{\mathrm{b}}$ represents the depth of the water column from the DEM corrected for tidal state and the height of the seagrass canopy (if present), which averaged $0.5 \mathrm{~m}$ across the study area. The relative transmittance of $L_{\mathrm{u}}$ through the air water interface $(t)$ was approximated as 0.54 (Mobley 1994). The apparent optical properties, $K_{L_{\mathrm{u}}}$ and $K_{\mathrm{d}}$, were modeled
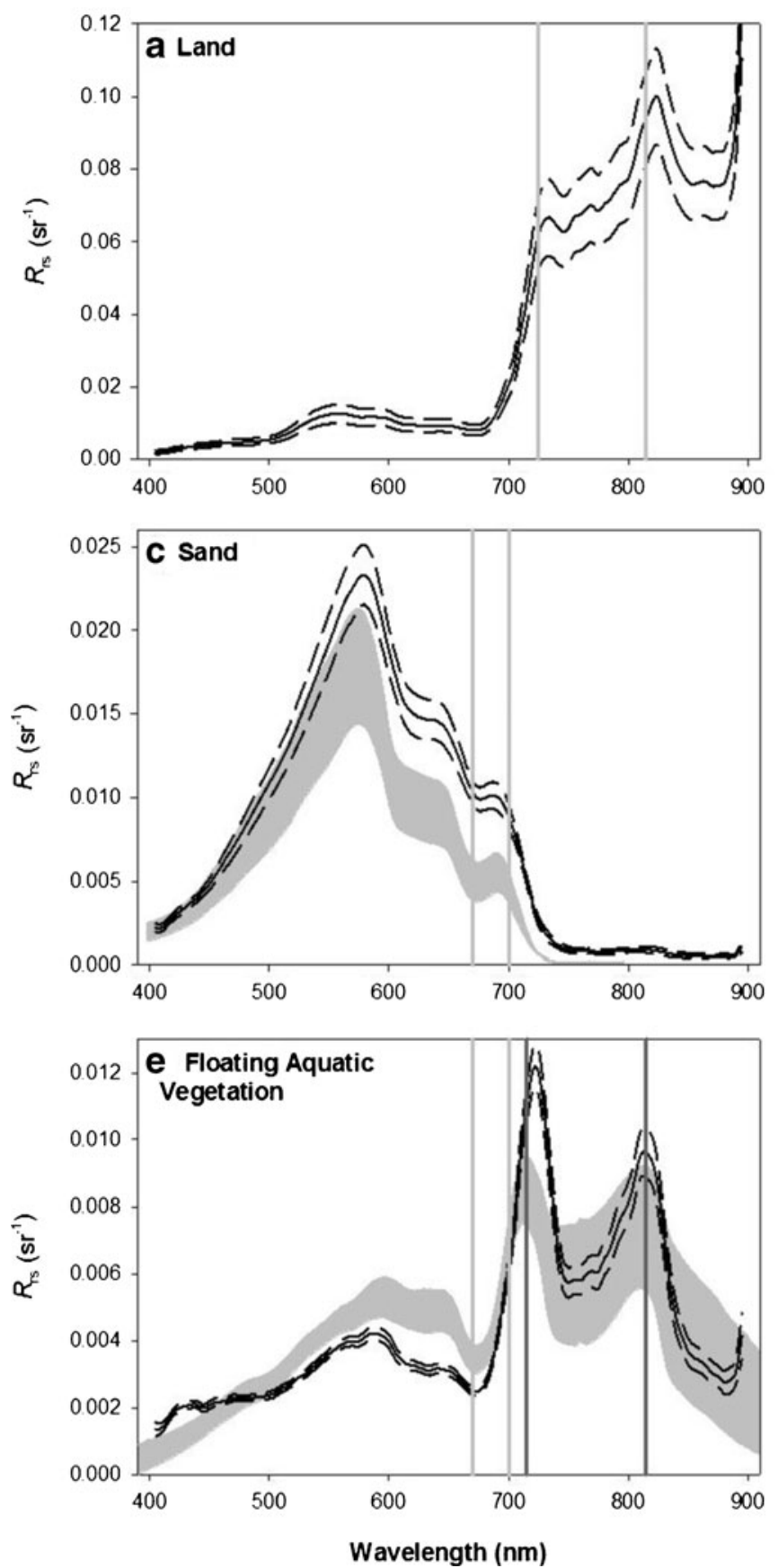

Fig. 4 Remote sensing reflectance spectra measured from in situ (shaded area mean $\pm 1 \mathrm{SE}$ ) and SAMSON instrumentation (solid lines mean \pm 1 $\mathrm{SE}$ ), over six different targets visible in the SAMSON imagery. a Terrestrial vegetation (no in situ spectra were measured). b Optically deep water. from Hydrolight ${ }^{\circledR}$ simulations using IOPs measured in situ using the ac-9 (Fig. 1).

Calculation of Benthic Production

Daily seagrass production was estimated using a series of transfer coefficients that convert LAI into fresh biomass, dry biomass (Sfriso and Ghetti 1998; van Tussenbroek 1998),
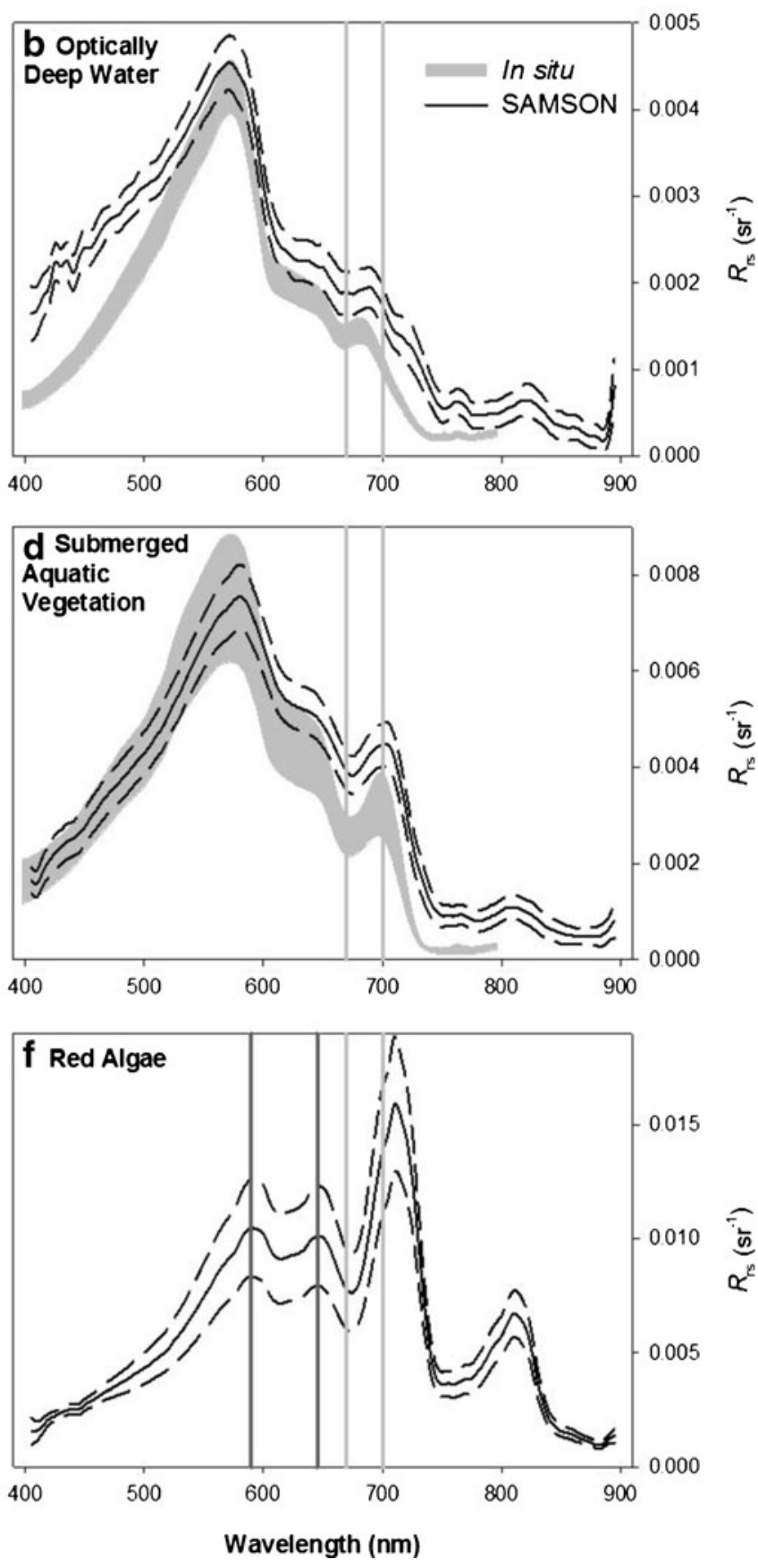

c Submerged sand. d Submerged aquatic vegetation. e Floating aquatic vegetation. f Red benthic algae (no in situ spectra were measured). The locations of bands used in classification are highlighted in each figure 
organic carbon (Hemminga and Duarte 2000), and finally to a growth rate (Duarte and Chiscano 1999):

$$
\begin{aligned}
\text { fresh wt }(\mathrm{g} \mathrm{FW})= & 500\left(\mathrm{~g} \mathrm{~m}^{-2} \text { leaf }\right) \\
& \times \operatorname{LAI}\left(\mathrm{m}^{2} \text { leaf } \mathrm{m}^{-2} \text { seebed }\right)
\end{aligned}
$$

dry $w t(g$ DW $)=$ fresh wt $\times 0.2\left(\mathrm{~g} \mathrm{DW} \mathrm{g}^{-1} \mathrm{FW}\right)$

$\operatorname{organic} \operatorname{carbon}(\mathrm{g} \mathrm{C})=\operatorname{dry} \operatorname{wt}(\mathrm{g} \mathrm{DW})$

$$
\times 0.35\left(\mathrm{~g} \mathrm{C} \mathrm{g}^{-1} \mathrm{DW}\right)
$$

growth rate $\left(\mathrm{gC} \mathrm{d}^{-1}\right)=$ organ carbon $\times 0.03$

Effects of Image Resolution on Retrieval of Seagrass Distribution

The effect of spatial resolution on the retrieval of seagrass ecosystem properties was explored by re-processing the atmospherically corrected imagery at 10,20,40, and $60 \mathrm{~m}$ resolution using the spatial re-sampling tool in ENVI (Ver. 4.6). The coarsened images were re-processed as described above for determination of seagrass distribution, LAI, and system-wide productivity. Class metrics (number of patches, mean patch area, shape index, and interspersion index) were calculated for each resolution using FRAGSTATS v4: Spatial Pattern Analysis Program for Categorical and Continuous Maps (http://www.umass.edu/landeco/research/fragstats/ fragstats.html). Shape index is equal to 1 when the patch is square and increases as patch shape becomes irregular. The interspersion index is based on patch adjacencies; higher values result from landscapes in which the patches have low connectivity; low values indicate fewer patches with high connectivity.

\section{Results}

Analysis of Reflective Targets from In Situ and Airborne Data

In situ $R_{\mathrm{rs}}$ spectra collected from ODW, unvegetated sand (sand), SAV, and FAV were equivalent to the remotely sensed SAMSON $R_{\mathrm{rS}}$ spectra, in both shape and magnitude (Fig. 4). The reflectance of terrestrial vegetation (SAMSON imagery only) generated a strong red edge that remained high across the NIR (Fig. 4a). Reflectance spectra for ODW, sand, and SAV targets peaked at green wavelengths around $580 \mathrm{~nm}$ (Fig. 4b-d), due to water column absorption of blue and red light. ODW presented a very dark target in which $R_{\mathrm{rs}}$ did not exceed $0.005 \mathrm{sr}^{-1}$ across the whole spectrum (Fig. 4b). Unvegetated submerged sand was an order of magnitude brighter at $580 \mathrm{~nm}$ than ODW, although the spectral shapes were similar (Fig. 4c). The characteristic feature distinguishing submerged seagrass (hereafter referred to as SAV) from bare sand and ODW was the presence of a peak at $700 \mathrm{~nm}$ (Fig. 4d), a residue of the "red edge" commonly exhibited by plants, but in this case attenuated by the overlying water column. The $R_{\mathrm{rs}}$ at $580 \mathrm{~nm}$ for SAV was intermediate in brightness between sand and ODW. Peaks at 705 and $810 \mathrm{~nm}$ (residuals of the "red edge") were observed in pixels containing seagrass leaves floating at the sea surface during low tide (hereafter referred to as FAV) in the shallow southern sections of the bay (Fig. 4e). Red algal spectra with peaks at 590 and $645 \mathrm{~nm}$ were also observed in the SAMSON imagery in shallow intertidal areas, but not visited during field work (Fig. 4f).

NDVI (Eq. 2) were consistently positive for all marine vegetation (SAV, FAV, and red algae), ranging from a minimum of 0.05 to a maximum of 0.18 (Fig. 4d-f). NDVIs from sand and ODW were significantly lower (one-way ANOVA $F(1,33)=91, p<0.01)$, consistently negative, and ranged from -0.096 to -0.02 to (Fig. $4 b, c$ ). Optically deep water was characterized by both $R_{\mathrm{rs}}$ values consistently $<0.003 \mathrm{sr}^{-1}$ at $710 \mathrm{~nm}$ and negative NDVIs. Floating aquatic vegetation was further distinguished from SAV and red algae using values of 1.2 or greater in the ratio between peaks in reflectance at 715 and $815 \mathrm{~nm}$ (Fig. 4e). The double reflectance peak at 590 and $645 \mathrm{~nm}$ was diagnostic for red algae observed in shallow intertidal regions (Fig. 4f). All remaining vegetated marine pixels were classified as SAV, which was consistent with diver observations in the bay and also with the spectral shape of the pixels mapped as SAV compared to our previous studies (Dierssen et al. 2003, 2010). In summary, the NDVI and band ratios provided

Table 3 Classification accuracy matrix (Congalton 2005) with the diagonal values (bold) indicating the number of stations that were accurately classified in each category

\begin{tabular}{lllll}
\hline & & \multicolumn{2}{l}{ Modeled } & \\
\cline { 3 - 5 } & & Seagrass & Sand & Optically deep \\
\hline \multirow{2}{*}{ Measured } & Seagrass & $\mathbf{9 2}$ & 0 & 0 \\
& Sand & 0 & $\mathbf{6}$ & 0 \\
& Optically deep & 0 & 0 & $\mathbf{2 4}$ \\
\hline
\end{tabular}

Values outside the diagonal would have been misclassified 
rigorous diagnostics for differentiating SAV, FAV red algae, sand and ODW (Table 3).

The resulting classification algorithm yielded $3.4 \mathrm{~km}^{2}$ of FAV, $5.3 \mathrm{~km}^{2}$ of red algae, and $14.9 \mathrm{~km}^{2}$ of SAV in the shallow margins of the bay, totaling $23.6 \mathrm{~km}^{2}$ of vegetation, plus $13.8 \mathrm{~km}^{2}$ of optically shallow sand fringing the deeper edges of the SAV beds and in several large sand banks across the southern end of the bay (Fig. 5). Some areas of intermediate brightness were visible in the imagery in approximately $2 \mathrm{~m}$ water on the deep edge of SAV zones but were not classified as optically shallow by the algorithm. Since there were no field stations in these areas, these possible classification errors were not included in the error matrix.

\section{Water Column Optical Properties}

Absorption by CDOM $\left(a_{\mathrm{g}}\right)$ dominated the total absorption at $440 \mathrm{~nm}$ in June $2006\left(65 \%\right.$ of $a_{\mathrm{g}}$ ) and September 2006 (72\% of $a_{\mathrm{g}}$; Fig. $\left.6 \mathrm{a}-\mathrm{c}\right)$. Bulk particulate material of both non-algal and algal origin was responsible for the remaining absorption

Fig. 5 Mapped distributions of red algae, submerged aquatic vegetation $(S A V)$, floating aquatic vegetation $(F A V)$, and sand benthic types identified and overlaid on the high resolution SAMSON pseudo-true color image of the Saint Joseph's Bay

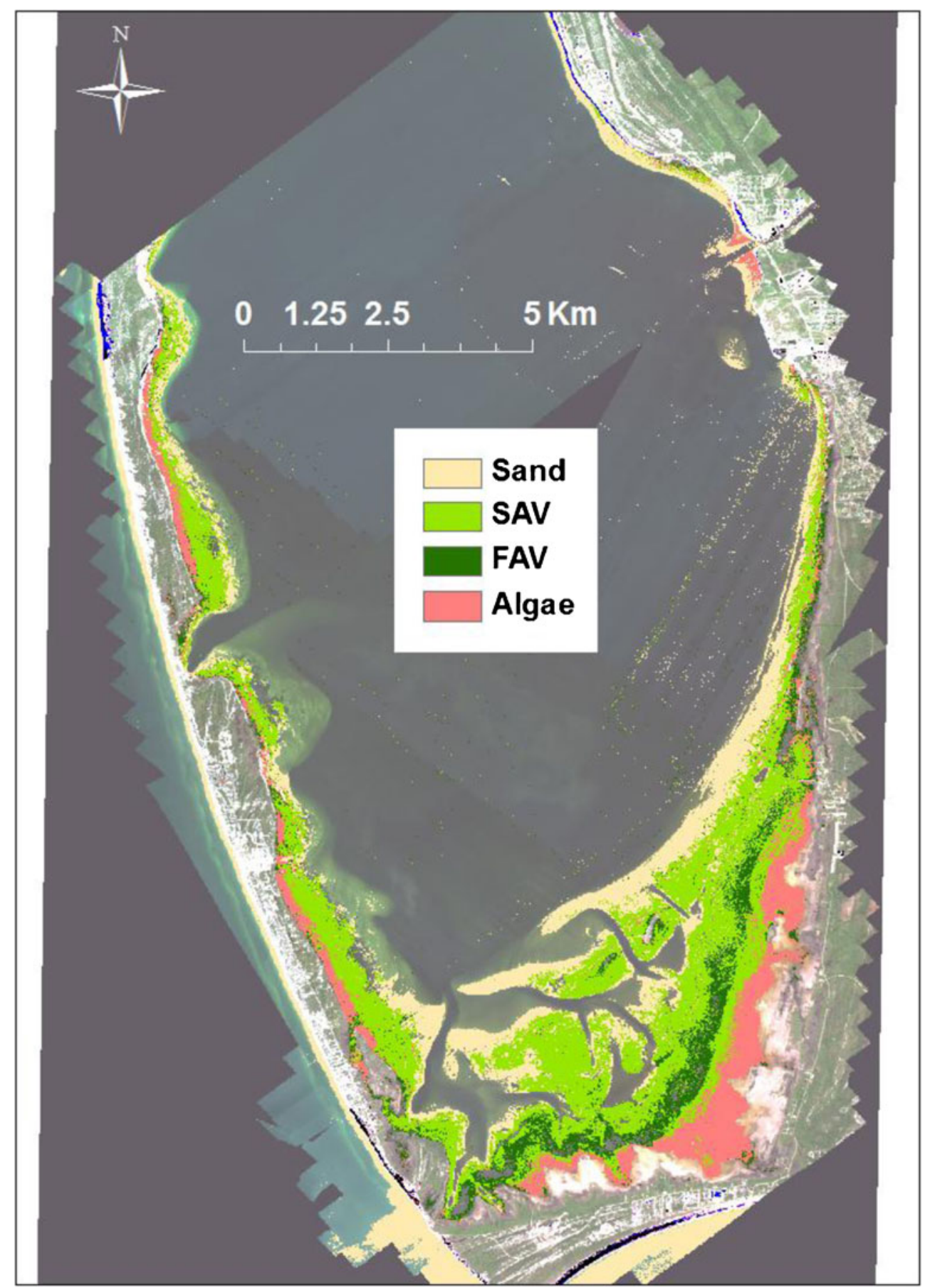



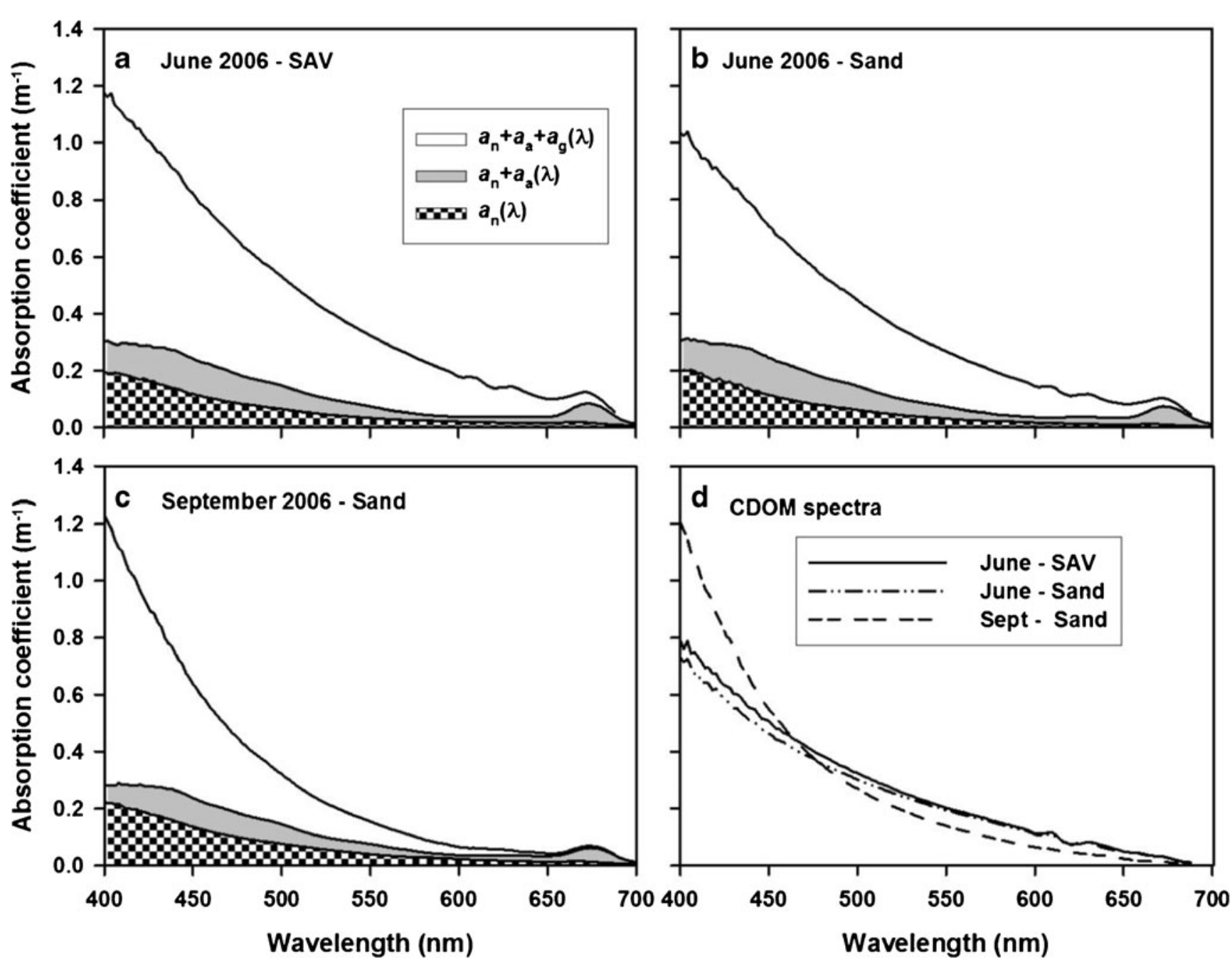

Fig. 6 Cumulative plots of water column absorption components. a June 2006 over SAV. b June 2006 over bare sand areas. c September 2006 over bare sand areas. Symbols are non-algal $\left(a_{\mathrm{n}}\right.$; hatched), non-algal plus algal $\left(a_{\mathrm{n}}+a_{\mathrm{a}} ;\right.$ gray $)$, and non-algal, algal, and colored dissolved organic material

$\left(a_{\mathrm{n}}+a_{\mathrm{a}}+a_{\mathrm{g}}\right.$; white). d Comparison of mean colored dissolved organic material absorption between June 2006 inside and outside of SAV areas and September 2006 outside of SAV areas

not attributable to water. The presence of seagrass did not affect the composition of absorbing compounds in the water column (Fig. 6a, b). However, between June and September 2006, absorption by CDOM increased, and the spectral slope of $a_{\mathrm{g}}$ nearly doubled from $0.004 \pm \mathrm{SE} 0.0003$ to $0.007 \pm \mathrm{SE}$ 0.0004 (Fig. 6d). The median in situ bulk water column absorption $\left(a_{\mathrm{pg}}\right)$ also increased between June and September (Fig. 7a) in the blue and green region of the spectrum (412 to $555 \mathrm{~nm}$, one-way ANOVA, $p<0.05)$. However, the similarity in $a_{\mathrm{pg}}$ at 650 and $676 \mathrm{~nm}$ between the two time periods indicates that the differences in the blue part of the spectrum resulted almost exclusively from an increase in CDOM absorption, but not phytoplankton or non-algal particulate absorption $\left(a_{\mathrm{p}}\right)$. Despite the increase in $a_{\mathrm{pg}}$, beam attenuation ( $c_{\mathrm{pg}}=$ absorption plus scattering) decreased across the visible spectrum between June and September (Fig. 7b, oneway ANOVA, $p<0.05$ ), indicating that the particulate scattering coefficient $(b)$ decreased (Fig. 7c). Thus, the increase in diffuse attenuation $\left(K_{\mathrm{d}}\right)$ (Fig. $7 \mathrm{~d}$ ) between June to September resulted from an increase in absorption by CDOM rather than scattering by suspended particles.

\section{Suspended Constituents of the Water Column}

There was no significant difference in the TSM load over bare sand areas vs. those with SAV in June 2006 (Fig. 8a, ANOVA $p<0.1$, mean $5.11 \pm 0.43 \mathrm{mg} \mathrm{m}^{-3}$ ). September TSM loads were significantly lower than in June (Fig. 8a, ANOVA $p>0.05$, mean $3.03 \pm 0.41 \mathrm{mg} \mathrm{m}^{-3}$ ). As with TSM, there were no significant differences in $\mathrm{Chl} a$ concentration between vegetated and unvegetated areas in June. Unlike TSM, Chl a concentrations did not differ significantly between June and September (Fig. 8b, ANOVA $p<0.1$ ). 

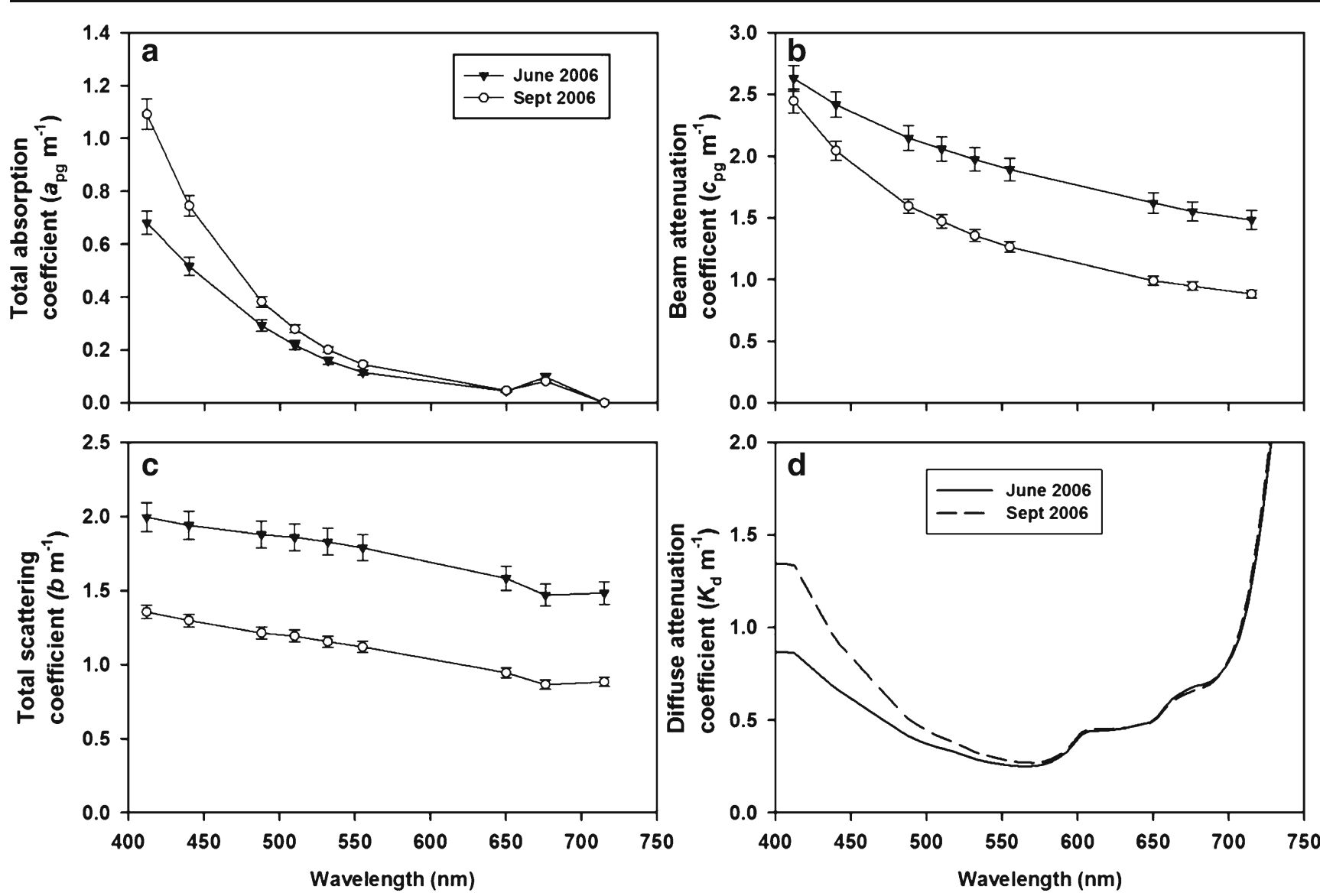

Fig. 7 In situ water column inherent optical properties from June and September 2006. Error bars indicate $\pm 1 \mathrm{SE}$ of the mean. a Total absorption coefficient $\left(a_{\mathrm{pg}}\right)$. b Beam attenuation coefficient $\left(c_{\mathrm{pg}}\right)$. $\mathbf{c}$ Total scattering coefficient $(b)$. All inherent optical properties were measured at nine

wavelengths (412, 440, 488, 510, 532, 555, 650, 676, $715 \mathrm{~nm})$ using an $a c-9$ (Wetlabs) package deployed at the surface. d Diffuse attenuation coefficient $\left(K_{\mathrm{d}}\right)$ modeled using Hydrolight based on measured $a_{\mathrm{pg}}$ and $c_{\mathrm{pg}}$

Fig. 8 Mean and standard error of a total suspended material and b chlorophyll $a$ concentrations from June and September 2006 deployments

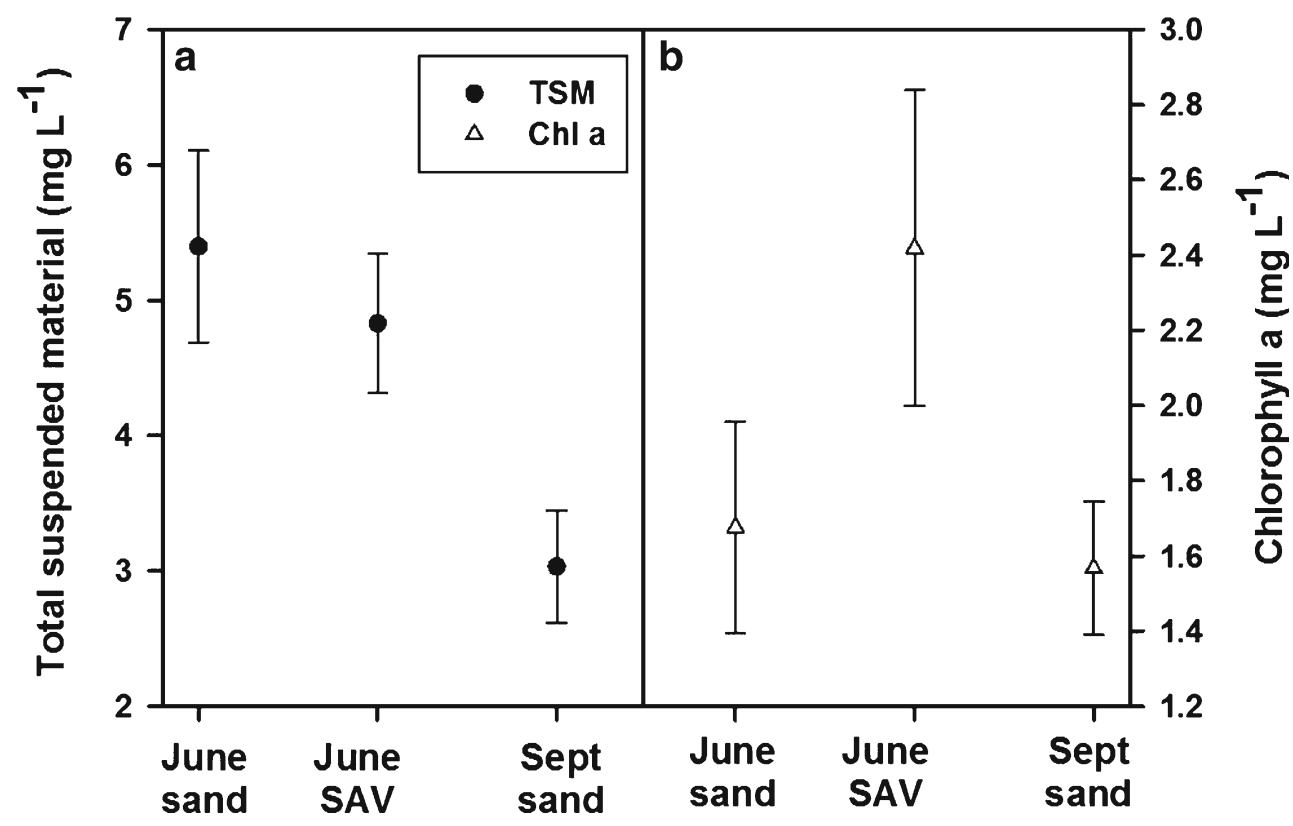


Modeling Bottom Reflectance $\left(R_{\mathrm{b}}\right)$

The NDVI was useful for identifying vegetation, but determining seagrass density across the aquatic landscape required elimination of the distorting effects of the overlying water column to accurately quantify bottom reflectance. The overall magnitude and spectral shape of $R_{\mathrm{b}}$ retrieved by removing water column effects (Eq. 5) over seagrass and sand were consistent with direct measurements obtained from the DOBBS (Fig. 9). The RMSE between measured and modeled spectra was $2.6 \%$ at $555 \mathrm{~nm}$ and provided confidence in the measured optical properties and the atmospheric correction of the imagery. The strong negative relationship between logtransformed $R_{\mathrm{b}}(555)$ and shoot density expressed as LAI $\left(r^{2}=\right.$ 0.81, Fig. 10) provided the mathematical basis for predicting seagrass abundance from the digital imagery. The slope of the relationship for stations observed in this study $(-3.14 \pm 0.28)$ was statistically identical to that reported for Bahamian populations $(-3.05 \pm 0.26)$ by Dierssen et al. (2003). The $X$-intercept for SJB $(-0.98 \pm 0.19)$, however, was significantly lower than that observed by Dierssen et al. (2003) for Bahamian seagrass $(-2.64 \pm 0.37)$ and most likely represents the difference in reflectivity of the siliciclastic sands of SJB relative to the carbonate sediments of the Great Bahama Bank (Dierssen
Fig. 9 Measured and modeled bottom reflectance $\left(R_{\mathrm{b}}\right)$ over submerged aquatic vegetation and sand

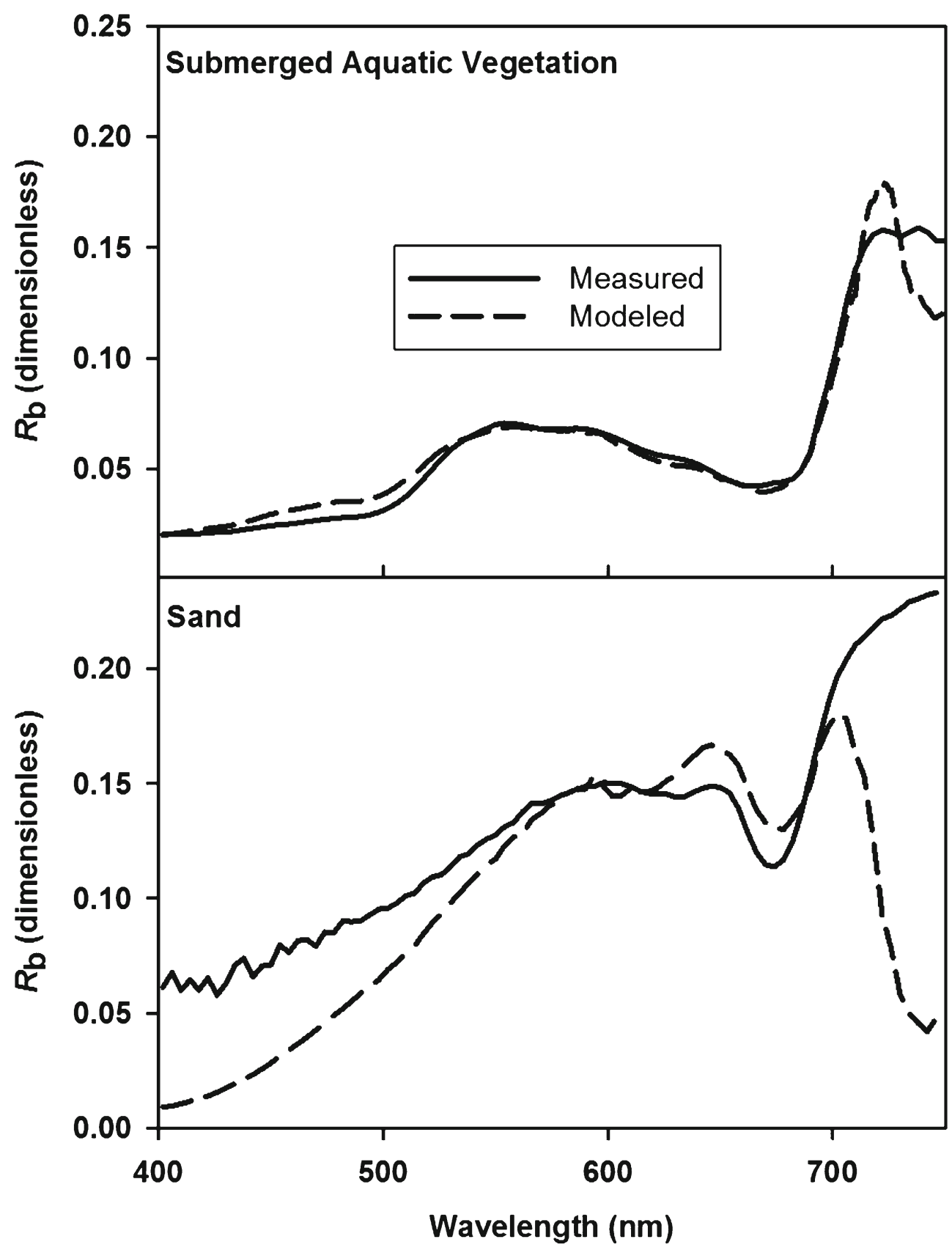


Fig. 10 In situ measurements of $R_{\mathrm{b}}(555)$ and leaf area index from Saint Joseph's Bay. Data are averaged from randomized sampling of within $20 \mathrm{~m}$ of a central location and are shown with \pm 1 standard error bars. The regression for this combined dataset was used in the retrieval of leaf area index from modeled $R_{\mathrm{b}}(555)$. The relationship between LAI and $R_{\mathrm{b}}(555)$ for Bahamas seagrass (Dierssen et al. 2003) is provided for reference
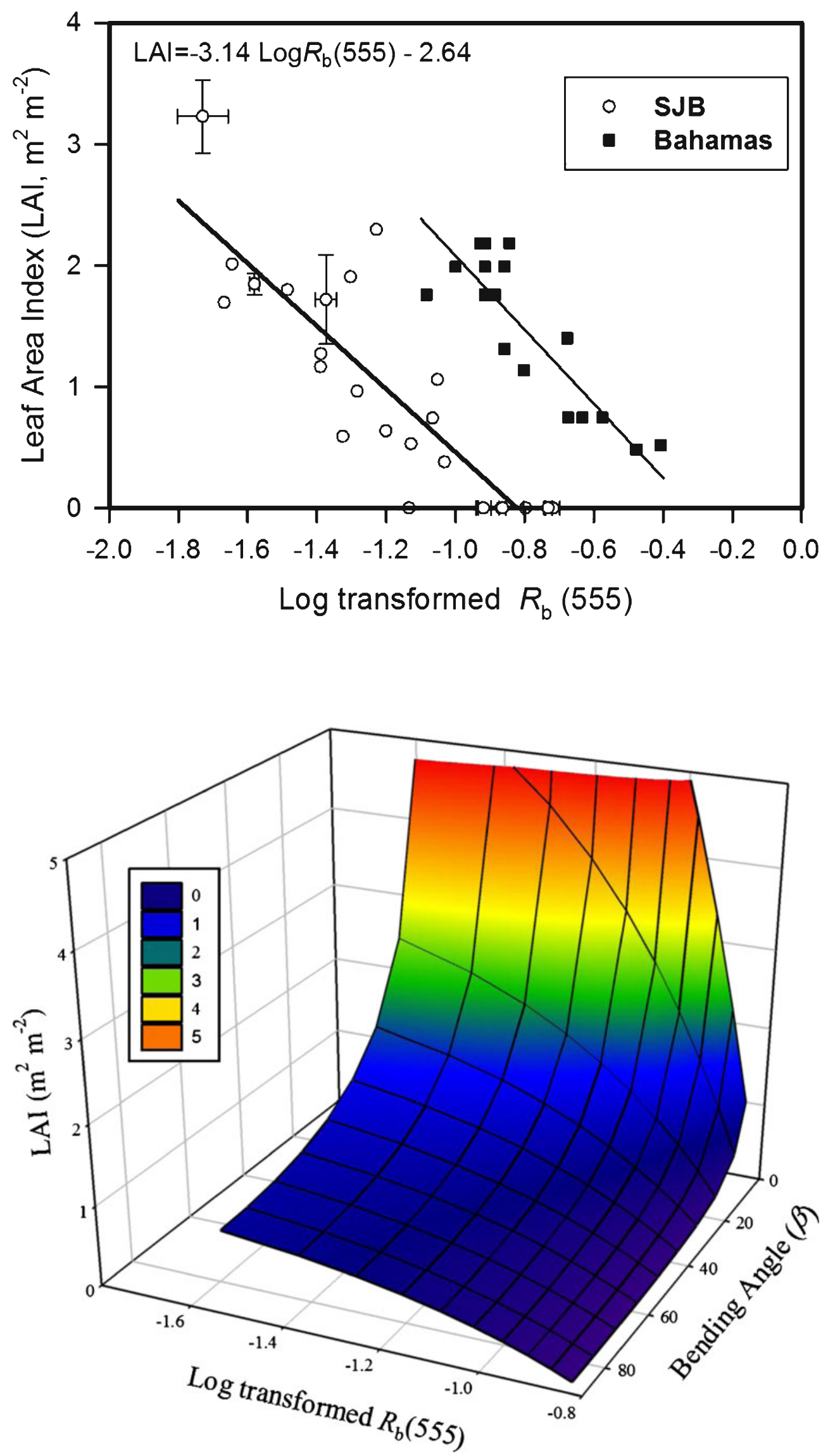

Springer
Fig. 11 Modeled data

representing the effect of bending angle of seagrass shoots on the relationship between $R_{\mathrm{b}}(555)$ and leaf area index 
et al. 2003) (Fig. 10). However, linearity of the $R_{\mathrm{b}}$ vs. LAI slope can be sensitive to the geometric orientation of the submerged plant canopy. The relationship is linear over the largest range of LAI when the canopy is nearly vertical $\left(<25^{\circ}\right)$ relative to the viewing angle (Fig. 11). Although SAMSON's air-incident viewing angle of $23^{\circ}$ is close to the $25^{\circ}$ threshold for non-linearity, Snell's law reduced the in-water viewing angle to only $9^{\circ}$, well within the linear region. However, the LAI required to saturate $R_{\mathrm{b}}$ (555) decreases as the leaves become more horizontal relative to the viewing angle. Such large bending angles can occur in strong unidirectional currents and particularly during low tides that create a floating surface canopy (Fig. 12).

The mean seagrass LAI retrieved from SAMSON was $2.0 \pm 0.6 \mathrm{~m}^{2} \mathrm{~m}^{-2}$ (Fig. 13). No seagrass signatures were detected on the ocean side of the peninsula that separates the bay from the Gulf of Mexico. Seagrass LAI measured in situ ranged between 1 and $2 \mathrm{~m}^{2} \mathrm{~m}^{-2}$ across the bay with a maximum around $3.3 \mathrm{~m}^{2} \mathrm{~m}^{-2}$ (Table 2). Large sections of seagrass meadows in the very shallow southern end of the bay were identified as FAV from which LAI could not be retrieved directly because of signal saturation (Fig. 11). In situ measurements of seagrass density within these FAV areas produced a mean LAI of $2.3 \pm 0.42 \mathrm{~m}^{2} \mathrm{~m}^{-2}$.

\section{Calculation of Benthic Production}

The conversion of remotely sensed LAI into seagrass carbon yielded $17,705 \mathrm{t}$ of seagrass $\mathrm{C}$ in $\mathrm{SJB}$, distributed as $83 \mathrm{t} \mathrm{C} \mathrm{km}^{-2}$ of SAV and $70 \mathrm{t} \mathrm{C} \mathrm{km}^{-2}$ of FAV (Table 4). Assuming a daily growth rate of $3 \%$ (Zieman et al. 1989), the seagrass population represents a carbon production rate for the entire bay of $37.1 \mathrm{t} \mathrm{day}^{-1}$. Annually, this represents a

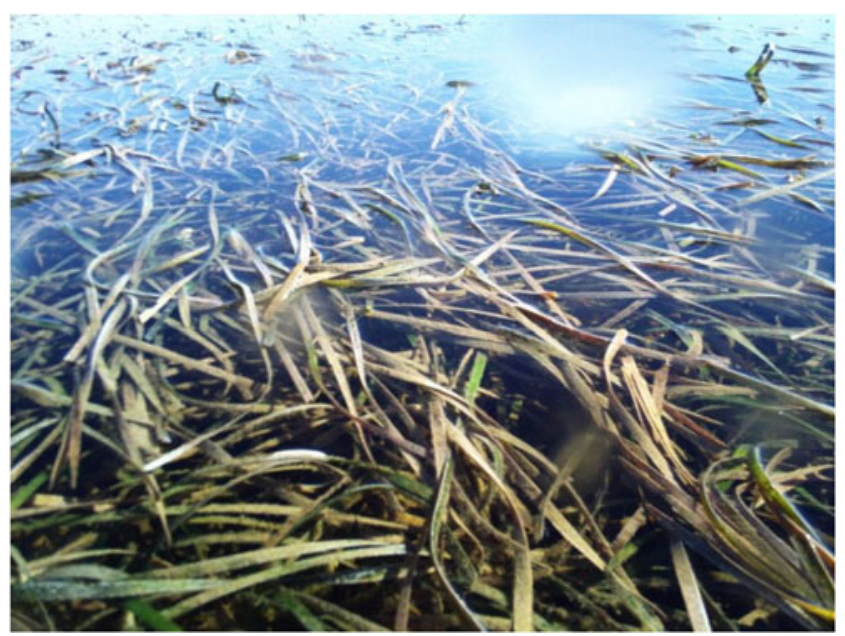

Fig. 12 Photograph of seagrass canopy (FAV) in Saint Joseph's Bay at low tide taken in seagrass meadow south of station 6 production rate of $13,570 \mathrm{t} \mathrm{C}$ year $^{-1}$. By comparison, we estimate phytoplankton production within the bay to be about 19,614 t C year ${ }^{-1}$, based on an average Chl $a$ concentration of $1.7 \mathrm{mg} \mathrm{m}^{-3}$ and euphotic depth of $10.9 \mathrm{~m}$ (defined by the depth where $E_{\mathrm{d}}(z)=0.1 E_{\mathrm{d}}(0)$ and average measured $K_{\mathrm{d}}(\mathrm{PAR})$ of $0.42 \mathrm{~m}^{-1}$ ). Thus, although seagrass occupies only $17 \%$ of the surface area, they are likely responsible for $41 \%$ of the annual primary production of Saint Joseph's Bay.

\section{Effects of Image Resolution on Retrieval of Seagrass Distribution}

Coarsening the spatial resolution of the imagery from 1 to $10 \mathrm{~m}$ decreased retrieval of biomass for SAV by about $10 \%$, but further coarsening up to $60 \mathrm{~m}$ pixels did not produce any further change in retrieval bias (Fig. 14a, b). Degrading the spatial resolution increased the biomass retrieval of FAV, a much brighter target than SAV. Since SAV was more abundant than FAV, coarsening the spatial resolution decreased the estimate of total vegetation by $7 \%$. The same pattern was seen in retrieval of area; SAV area was underestimated by $8 \%$ and red algae area by $4 \%$ (Fig. 14b). Conversely the total area of brighter targets such as sand and FAV were overestimated by 10 and $12 \%$, respectively. Seagrass in the southern section of the bay was distributed primary as one large patch, representing about $70 \%$ of the total vegetated area, and $95 \%$ of total vegetated area was distributed into 20 patches or less, regardless of image resolution. Larger pixel size resulted in the merger of SAV into fewer but larger patches that were more irregular in shape and more aggregated within the landscape (Table 5).

\section{Unusual Geomorphic Features}

In addition to quantifying the distribution of SAV, the imagery revealed nearly 1,000 uniform dark patches with a mean diameter of $18 \mathrm{~m}( \pm \mathrm{SE} 1 \mathrm{~m})$ along the southeastern margin of the bay (Fig. 15). The largest dark patch was nearly $60 \mathrm{~m}$ in diameter, and the smallest detected by the imagery was $1 \mathrm{~m}$. In situ inspection of a few patches revealed them to be optically deep (geometric depths $>2 \mathrm{~m}$ ) hemispherical depressions, surrounded by a narrow ring of sand which graded into seagrass on the surrounding flats. The extent of these holes was not evident from initial in situ surveys, but local knowledge indicated that they are old aerial bomb craters resulting from military training activity during World War II.

\section{Discussion}

The level of spectral detail provided by SAMSON enabled us to distinguish fine scale spectral features necessary for the 
Fig. 13 Distribution of seagrass leaf area index from 0 to $3 \mathrm{~m}^{2}$ leaf $\mathrm{m}^{-2}$ seafloor estimated across Saint Joseph's Bay, Florida, USA from SAMSON hyperspectral imagery

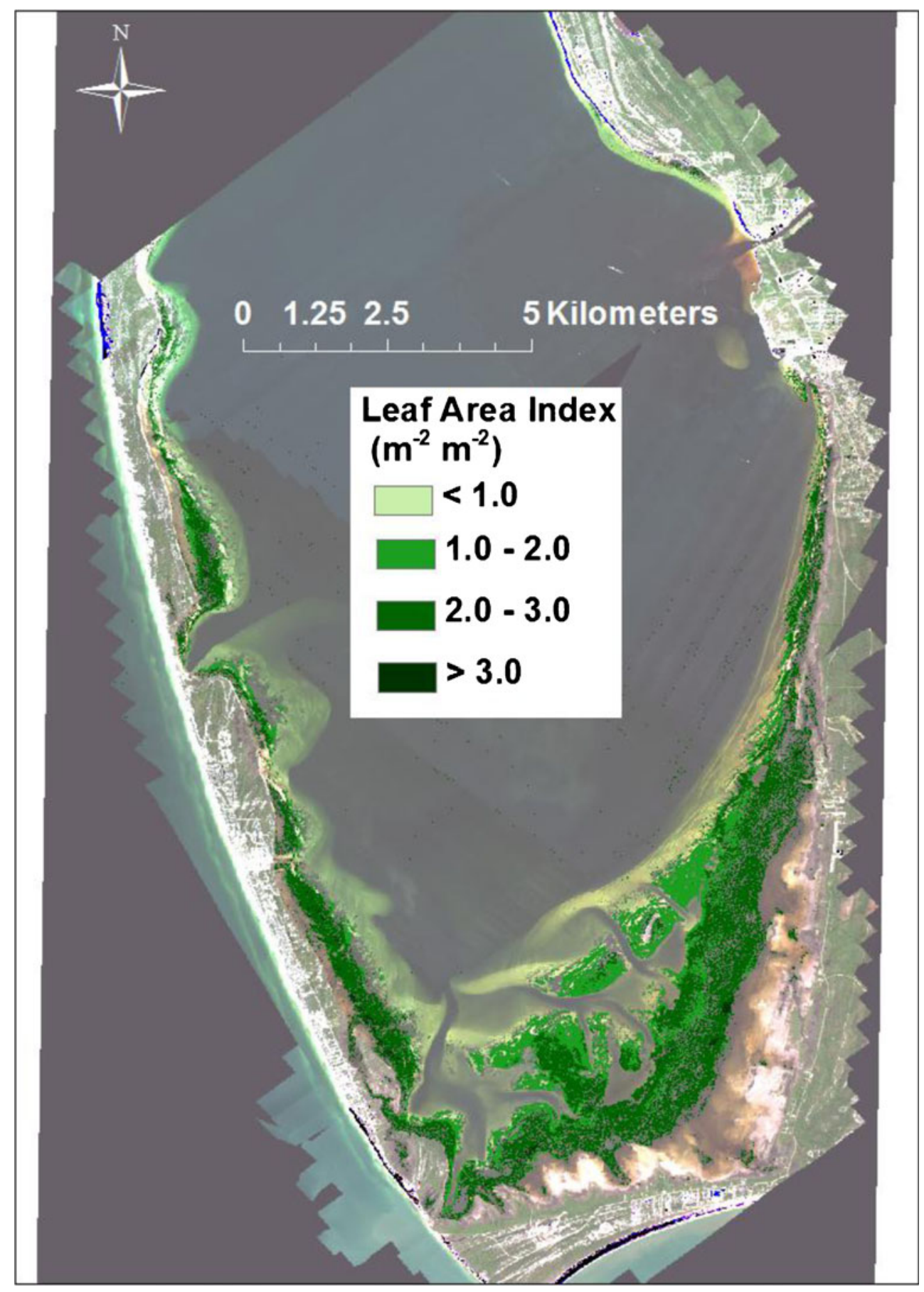

retrieval and separation of submerged aquatic vegetation, floating aquatic vegetation, red algae, bare sand, and optically deep water in the highly productive and highly colored coastal waters of Saint Joseph's Bay, Florida. Although interspecies differences in the spectral reflectance of seagrass have been identified in a lab setting (Fyfe 2003), we were unable to distinguish among seagrass species due to the mixed nature of the beds and the highly attenuating environment.
Look-up tables and inverse radiative transfer methods have proven to be successful in the retrieval of benthic types in the clear tropical waters of the Bahamas, Caribbean, and Australia (Lee et al. 1999; Dierssen et al. 2003; Kutser et al. 2006; Lesser and Mobley 2007; Dekker et al. 2011). However, the waters of SJB were an order of magnitude less transparent than those measured in the Great Bahamas Bank seagrass systems (Dierssen et al. 2010) and more attenuating than values observed in the Florida Bay seagrass meadows 
Table 4 Estimates of areal coverage, standing stocks and productivity of submerged aquatic vegetation, floating aquatic vegetation, benthic red algae, and phytoplankton within Saint Joseph's Bay, as determined from SAMSON imagery

\begin{tabular}{|c|c|c|c|c|}
\hline & SAV & FAV & $\begin{array}{l}\text { Red } \\
\text { algae }\end{array}$ & Phytoplankton \\
\hline Total area $\left(\mathrm{km}^{2}\right)$ & 14.9 & 3.4 & 5.3 & 116 \\
\hline Total fresh biomass (t) & 14,341 & 3,364 & No data & No data \\
\hline Total dry biomass $(\mathrm{t})$ & 2,686 & 673 & No data & No data \\
\hline Total carbon (t C) & 1,003 & 235 & No data & 107 \\
\hline $\begin{array}{l}\text { Carbon per unit area } \\
\left(\mathrm{t} \mathrm{C} \mathrm{km}^{-2}\right)\end{array}$ & 83 & 70 & No data & 0.9 \\
\hline Growth rate $\left(\right.$ day $\left.^{-1}\right)$ & $3 \%$ & $3 \%$ & No data & $50 \%$ \\
\hline Daily production ( $\mathrm{t} \mathrm{C}$ day $^{-1}$ ) & 30 & 7.1 & No data & 53 \\
\hline $\begin{array}{l}\text { Annual production } \\
\left(\mathrm{t} C \text { year }^{-1}\right)\end{array}$ & 10,992 & 2,578 & No data & 19,614 \\
\hline
\end{tabular}

$S A V$ submerged aquatic vegetation, $F A V$ floating aquatic vegetation

(McPherson et al. 2011). Thus, the ability to faithfully retrieve seabed reflectance and seagrass density reveals the versatility of this radiative transfer approach even for optically complex and fairly turbid coastal environments such as we encountered in SJB.

In addition to high spectral resolution, the high spatial resolution provided by SAMSON was important for characterizing landscape-scale statistics of seagrass distribution. Increasing pixel size causes the signals from bright targets (e.g., sand) to overwhelm dark ones (seagrass) in mixed pixels. As a result, increasing the pixel size above $10 \mathrm{~m}$ produced an underestimation of up to $8 \%$ in retrieved SAV and red algae area and an overestimation of 10 to $12 \%$ in retrieved FAV and sand area. In addition, the coarser spatial resolution caused patches to merge and become more uniform (spherical) in shape. The resulting loss of spatial complexity may have important implications for estimating patch dimension and connectivity, which are critical for understanding the effect of habitat fragmentation on survival of juvenile species (Hovel and Lipcius 2001) and the study of recruitment, spreading, infilling, and disturbance of seagrass meadows (Bell et al. 1999).

The need for routine coverage of coastal regions is moving us from airborne to spaceborne remote sensing platforms, but none of the orbiting sensors can, at present, provide the high spectral and spatial resolution of aircraft systems. Current sensors with fine spatial resolution $(\sim 2 \mathrm{~m})$ are multispectral (WorldView2) with 50- to 60-nm-wide bins which are ineffective for detecting the narrow spectral signatures $(\sim 10$ to $20 \mathrm{~nm}$ ) observed in the NIR that characterize submerged vegetation. Sensors with high spectral resolution (DLR's EnMap, ONR's HICO, and NASA's planned HyspIRI) have coarse spatial resolution (30 to $100 \mathrm{~m}$ ) which incurs errors in biomass and landscape scale statistics in heterogeneous coastal environments. Pan sharpening techniques that involve the merging of imagery from sensors with different spatial/ spectral capabilities may provide at pathway for developing merged data products with improved spatial resolution that may partially compensate for the limited capabilities of individual sensors (Garzelli et al. 2004; Akula et al. 2012).

This study was able to exploit a rich data set that enabled atmospheric correction of the SAMSON imagery and removal of the spectral distortions in $R_{\mathrm{rs}}$ caused by the overlying water column to achieve accurate estimates of bottom reflectance for all optically shallow pixels within the study area. Of particular importance in this analysis was the availability of an accurate DEM derived from the acoustic survey, as the required vertical resolution in bathymetry $(\sim 10 \mathrm{~cm})$ could not be derived from the passive optical remote sensing of these optically complex waters (Lee et al. 1999; Mobley et al. 2005). Future studies, however, should be able to repeat the analysis with less in situ data by inverting Eq. 5 for pixels containing bare sand to solve for $K_{\mathrm{d}}$ and $K_{L_{\mathrm{u}}}$, assuming constancy in the reflectance properties of bare sand and continued accuracy of our DEM.

The consistency of the $R_{\mathrm{b}}$ vs. LAI slope suggests a relationship that can transcend locations, at least for seagrass leaf reflectance, which, because of package effects, are not all that different optically (10-20\%), even though pigment concentrations can vary by $5 \times$ (Cummings and Zimmerman 2003; Zimmerman 2003). The intercept ( $\mathrm{LAI}=0$ ), however, is controlled by brightness of the underlying substrate, which can vary by an order of magnitude among sediments from bright carbonate sand $[R(555)=0.4$, Bahamas] to siliciclastic sand $[R(555)=0.2, \mathrm{SJB}]$ to fine siliciclastic muds $[R(555)=0.04$; Louchard et al. 2003; Zimmerman 2003].

Seagrasses continue to be an ecologically important component of SJB in terms of areal coverage, standing biomass, and total productivity. Prior mapping of seagrasses in SJB is limited to uniform distributions within polygons derived from aerial photography (McNulty et al. 1972), and dense, medium, and sparse classes are determined using a multispectral scanner (Savastano et al. 1984). These techniques yielded relative abundances and areal coverage but not absolute abundances. The high spatial and spectral resolution available from SAMSON provided absolute densities in terms of physical units and textural resolution including distinguishing densities on sand ripples and small-scale geographical resolution. When compared to these previous maps of seagrass coverage, areas of dense seagrass were still found to be dense and sparse areas still sparse, showing that seagrasses appear to be relatively stable in this area.

Despite high and apparently variable levels of CDOM, SAV populations appear to be relatively stable 
Fig. 14 Relationship between pixel size and retrieval of a biomass and $\mathbf{b}$ area of benthic types. Data are from the southern end of Saint Joseph's Bay; imagery was resampled using ENVI 4.6 to pixel sizes ranging from 10 to $60 \mathrm{~m}$. All data are plotted relative to retrieved values from the 1-m imagery
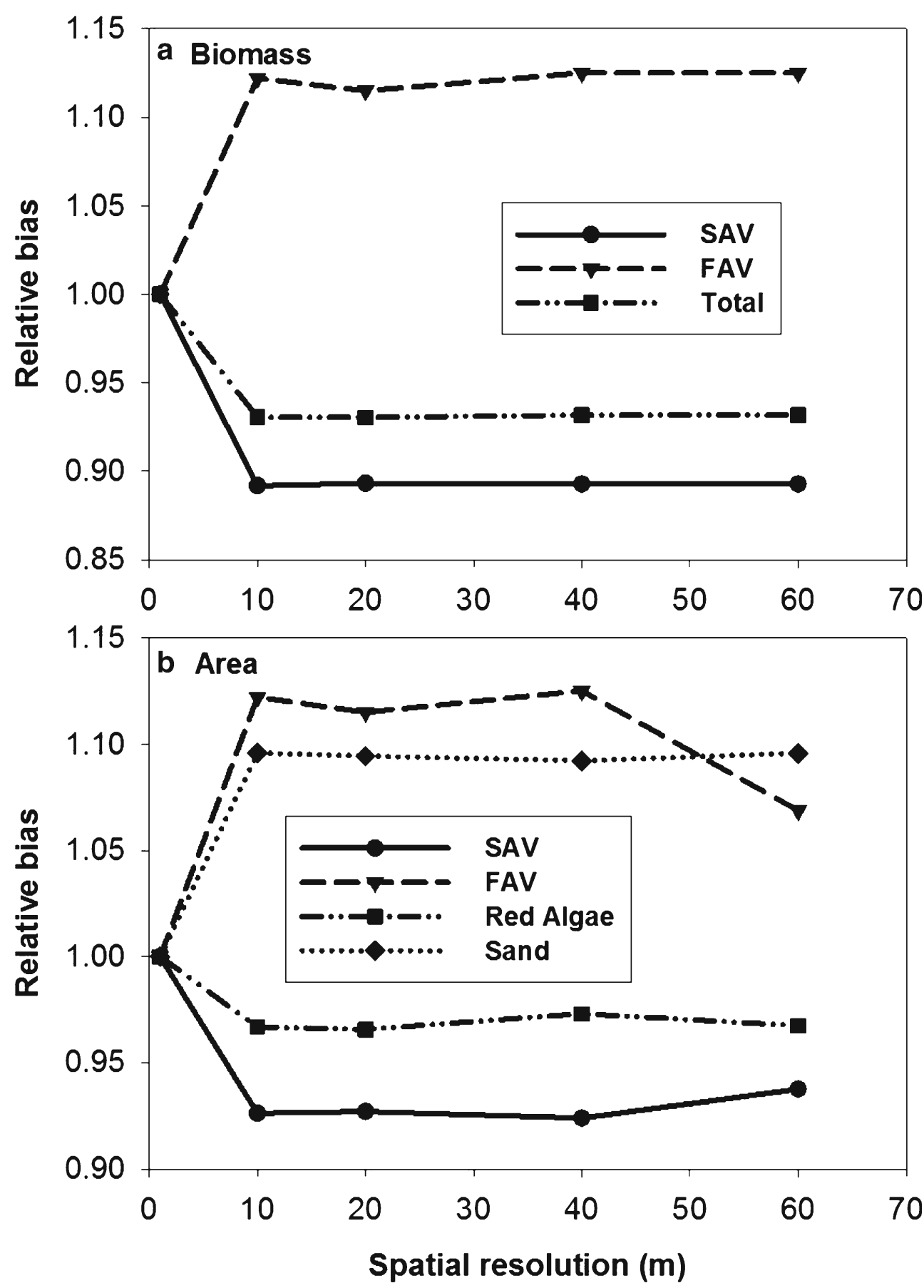

since at least 1972. Our estimate of $24 \mathrm{~km}^{2}$ is remarkably consistent with the estimate of $25.6 \mathrm{~km}^{2}$ derived from aerial photography in 1972 (McNulty et al. 1972) and a 1984 estimate of 23 to $24 \mathrm{~km}^{2}$ derived from an early multispectral airborne sensor (Savastano et al. (1984)). Assuming the limit for potential expansion of seagrasses in SJB is driven by the light environment, the average $K_{\mathrm{d}}(440)$ of $0.9 \mathrm{~m}^{-1}$ measured in this study was consistent with a $10 \%$ isolume located at $2.5 \mathrm{~m}$.
Reducing $K_{\mathrm{d}}$ (440) by half to $0.5 \mathrm{~m}^{-1}$ could increase the depth of the $10 \%$ isolume to $4.6 \mathrm{~m}$, but because of the relatively steep drop in bathymetry around the bay, doubling the light penetration would only increase the area of potential seagrass habitat by approximately $0.03 \mathrm{~km}^{2}$, less than $1 \%$ of the current estimate. This small increase in SAV habitat in response to improved water transparency is due primarily to the characteristic topography of SJB in which the deep central basin 
Table 5 Effect of pixel resolution on SAV patch metrics from the southern end of Saint Joseph's Bay, Florida, USA

\begin{tabular}{llllll}
\hline Class metric & $1 \mathrm{~m}$ & $10 \mathrm{~m}$ & $20 \mathrm{~m}$ & $40 \mathrm{~m}$ & $60 \mathrm{~m}$ \\
\hline Number of patches & 72,593 & 1,623 & 518 & 238 & 42,864 \\
Mean area $\left(\mathrm{m}^{2}\right)$ & 155 & 6,439 & 20,195 & 143 \\
Median area $\left(\mathrm{m}^{2}\right)$ & 1 & 100 & 400 & 71,572 \\
Maximum area $\left(\mathrm{m}^{2}\right)$ & $7,897,179$ & $7,323,200$ & $7,210,000$ & $7,259,200$ & 3,600 \\
Minimum area $\left(\mathrm{m}^{2}\right)$ & 1 & 100 & 400 & 1,600 & 1.54 \\
Shape index & 1.19 & 1.21 & $9,574,400$ & 3,600 \\
Interspersion index & 94 & 97 & 96 & 24 & 1.5 \\
\hline
\end{tabular}

The original 1-m resolution imagery was resampled using ENVI 4.6 to pixel sizes ranging from 10 to $60 \mathrm{~m}$. Patch metrics were calculated using FRAGS TATS v4: Spatial Pattern Analysis Program for Categorical and Continuous Maps. Available at the following web site: http://www.umass.edu/landeco/ research/fragstats/fragstats.html. The shape index is 1 for square patches and increases as patch shape becomes irregular. The interspersion index is a measure of patch adjacency; higher values result from landscapes in which the patches have low connectivity; low values indicate fewer patches with high connectivity

limits seagrass to the shallow sandy banks near the shore. Doubling the average $K_{\mathrm{d}}(440)$ to $1.8 \mathrm{~m}^{-1}$ would shoal the $10 \%$ isolume to $1.3 \mathrm{~m}$, resulting in an overall reduction in SAV area of $3.3 \%$. While this is a small fraction of the current area, the impact of increased light attenuation on SAV density within this survival zone is as yet undetermined. Maintaining the current optical properties should be a benchmark of the Florida coastal management.

Seagrass remote sensing is rapidly moving from the qualitative to the quantitative realm, with real ability to translate image properties into biogeochemical stocks and rates. The
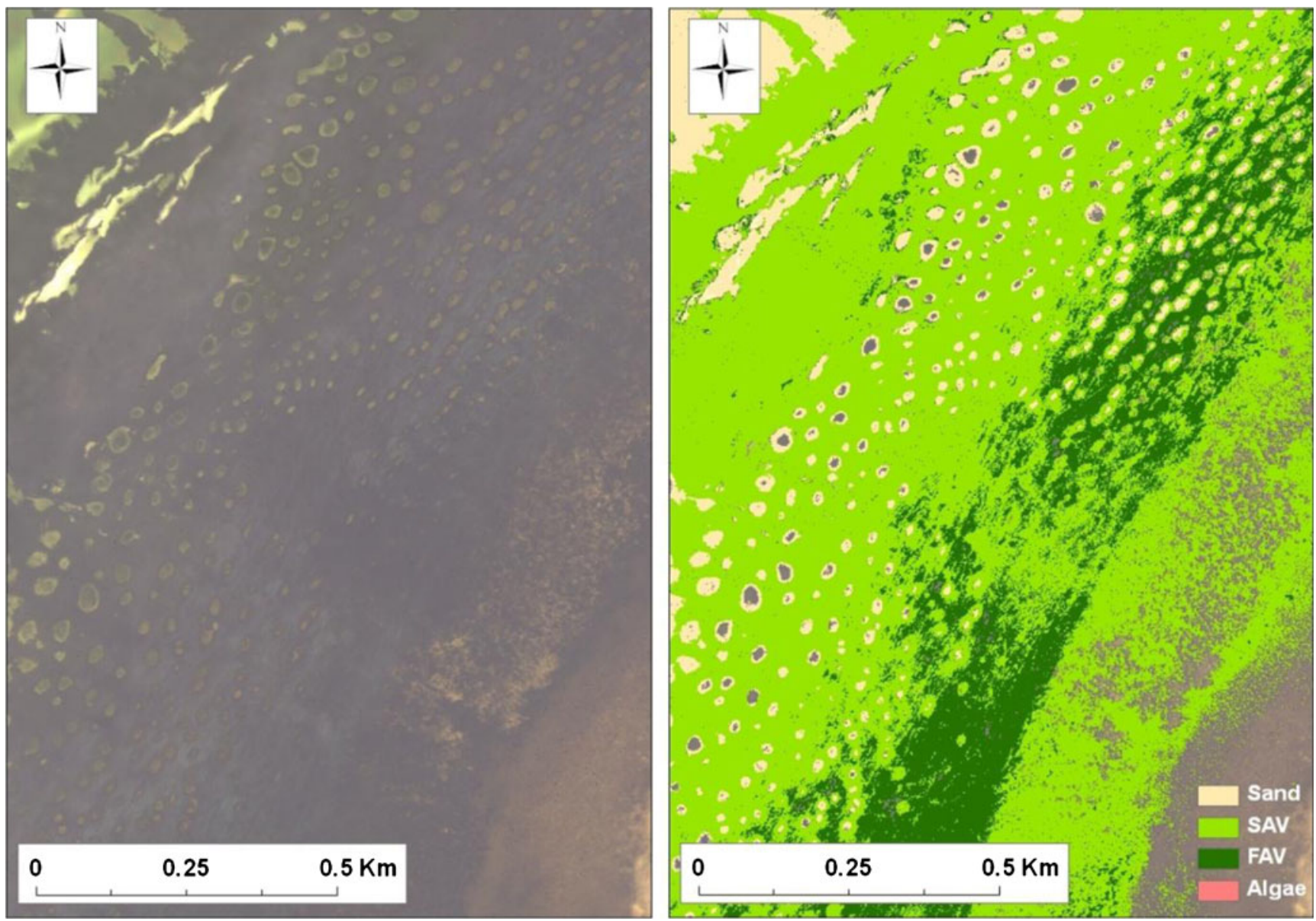

Fig. 15 Enlarged region from Fig. 13 showing unidentified craters (mean diameter $8 \mathrm{~m}$ ) distributed along the shallow southeast margin of the bay 
approach presented here represents an important advancement in understanding and interpreting system dynamics relative to semi-quantitative measures (i.e., spatial coverage of SAV pixels) derived from un-calibrated imagery such as aerial photography (Meehan et al. 2005). These advances will be important for our future ability to detect change and evaluate ecosystem health in the context of climate change that results in deteriorating coastal water quality, global warming, and ocean acidification.

Acknowledgments We thank D. Ruble, J. Cousins, M. Stoughton, C. Buonassissi, I. Nardello, J. Godfrey, and A. Branco for assistance in data collection. We also acknowledge the staff and facilities at the Preserve Center, St. Joseph's Bay State Buffer and Aquatic Preserves, Office of Coastal and Aquatic Managed Areas and the crew at Daly's Dock and Dive Centre, Port Saint Joe, FL. This work was supported by funding from NASA project NNG04GN84G and Florida DNR Coastal Aquatic Managed Areas.

\section{References}

Akula, R., R. Gupta, and M.R. Vimala Devi. 2012. An efficient PAN sharpening technique by merging two hybrid approaches. Procedia Engineering 30: 535-541. doi:10.1016/j.proeng.2012.01.895.

Bell, S.S., B.D. Robbins, and S.L. Jensen. 1999. Gap dynamics in a seagrass landscape. Ecosystems 2(6): 493-504. doi:10.1007/ s100219900097.

Bell, S.S., M.S. Fonseca, and N.B. Stafford. 2006. Seagrass ecology: New contributions from a landscape perspective. In Seagrasses: Biology, ecology and conservation, ed. A.W.D. Larkum, 625-645. the Netherlands: Springer.

Bissett, W.P., R.A. Arnone, C.O. Davis, T.D. Dickey, D. Dye, and D. Kohler. 2004. From meters to kilometers - a look at ocean color scales of variability, spatial coherence, and the need for fine scale remote sensing in coastal ocean optics. Oceanography 17(2): 32-43.

Bissett, P., R.A. Arnone, S. DeBra, D. Deterlie, D. Dye, G. Kirkpatrick, O. Schofield, and J. Walsh. 2005. Predicting the inherent optical properties and colored dissolved organic matter dynamics on the West Florida Shelf. Marine Chemistry 95: 199-233.

Brando, V.E., J.E. Anstee, M. Wettle, A. Dekker, S.R. Phinn, and C. Roelfsema. 2009. A physics based retrieval and quality assessment of bathymetry from suboptimal hyperspectral data. Remote Sensing of Environment 113: 15.

Buonassissi, C. J. and H. M. Dierssen. 2010. A regional comparison of particle size distributions and the power law approximation in oceanic and estuarine surface waters. Journal of Geophysical Research 115. doi:10.1029/2010JC006256.

Congalton, R. G. 2005. Thematic and positional accuracy assessment of digital remotely sensed data classification accuracy. Seventh Annual Forest Inventory and Analysis Symposium.

Cummings, M.E., and R.C. Zimmerman. 2003. Light harvesting and the package effect in the seagrasses Thalassia testudinum Banks ex König and Zostera marina L.: Optical constraints on photoacclimation seagrass. Aquatic Botany 75: 261-274.

Davis, C.O., J.H. Bowles, R.A. Leathers, D. Korwan, T.V. Downes, W.A. Snyder, W.J. Rhea, W. Chen, J. Fisher, P. Bissett, and R.A. Reisse. 2002. Ocean PHILLS hyperspectral imager: Design, characterization, and calibration. Optics Express 10(4): 210-221.

Dekker, A., V. Brando, J. Anstee, S.K. Fyfe, T. Malthus, and E. Karpouzli. 2006. Remote sensing of seagrass systems: Use of spaceborne and airborne systems. In Seagrasses: Biology, ecology and conservation, ed. A.W.D. Larkum and C.M. Duarte, 347-359. Dordrecht: Springer.

Dekker, A., S.R. Phinn, J. Anstee, P. Bissett, V.E. Brando, B. Casey, P. Fearns, J. Hedley, W. Klonowski, Z.P. Lee, M. Lynch, M. Lyons, and C.D. Mobley. 2011. Intercomparison of shallow water bathymetry, hydro-optics, and benthos mapping techniques in Australian and Caribbean coastal environments. Limnology and Oceanography: Methods 9: 396-425.

Dierssen, H.M., R.C. Zimmerman, R.A. Leathers, T.V. Downes, and C.O. Davis. 2003. Ocean color remote sensing of seagrass and bathymetry in the Bahamas Banks by high-resolution airborne imagery. Limnology and Oceanography 48(1, part 2): 444-455.

Dierssen, H.M., R.C. Zimmerman, L.A. Drake, and D.J. Burdige. 2010. Benthic ecology from space: Optics and net primary production in seagrass and benthic algae across the Great Bahama Bank. Marine Ecology Progress Series 411: 1-15. doi:10.3354/meps08665.

Duarte, C.M., and C.L. Chiscano. 1999. Seagrass biomass and production: A reassessment. Aquatic Botany 65: 159-174.

Ferwerda, J.G., J. De Leeuw, C. Atzberger, and Z. Vekerdy. 2007. Satellite-based monitoring of tropical seagrass vegetation: Current techniques and future developments. Hydrobiologia 591: 59-71.

Fyfe, S.K. 2003. Spatial and temporal variation in spectral reflectance: Are seagrass species spectrally distinct? Limnology and Oceanography 48(1): 15.

Gao, B.-C., M.J. Montes, Z. Ahmad, and C.O. Davis. 2000. Atmospheric correction algorithm for hyperspectral remote sensing of ocean color from space. Applied Optics 39(6): 887-896.

Gao, B.-C., M.J. Montes, and C.O. Davis. 2004. Refinement of wavelength calibrations of hyperspectral imaging data using a spectrum-matching technique. Remote Sensing of the Environment 90(4): 424-434.

Garzelli, A., Nencini, F., Alparone, L., Aiazzi, B. and S. Baronti. 2004. Pan-sharpening of multispectral images: A critical review and comparison. Geoscience and Remote Sensing Symposium. 1.

Gillanders, B.M. 2006. Seagrasses, fish and fisheries. In Seagrasses: Biology, ecology and conservation, ed. A.W.D. Larkum, R. Orth, and C.M. Duarte. the Netherlands: Springer.

Han, L., and D. Rundquist. 2003. The spectral response of Ceratophyllum demersum at varying depths in an experimental tank. International Journal of Remote Sensing 24(4): 859-864.

Harwell, M.C., and R.J. Orth. 2001. Influence of a tube-dwelling polychaete on the dispersal of fragmented reproductive shoots of eelgrass. Aquatic Botany 70: 1-7.

Hemminga, M.A., and C.M. Duarte. 2000. Seagrass ecology seagrass. Cambridge: Cambridge University Press.

Hovel, K.A., and R.N. Lipcius. 2001. Habitat fragmentation in a seagrass landscape: Patch size and complexity control Blue Crab survival. Ecology 82(7): 1814-1829. doi:10.1890/0012-9658(2001) 082[1814:HFIASL]2.0.CO;2.

Kendrick, G.A., B.J. Hegge, A. Wyllie, A. Davidson, and D.A. Lord. 2000. Changes in seagrass cover on success and Parmelia Banks, Western Australia between 1965 and 1995. Estuarine, Coastal and Shelf Science 50(3): 341-353. doi:10.1006/ecss.1999.0569.

Kirk, J.T.O. 1994. Light and photosynthesis in aquatic ecosystems photosynthesis. Cambridge: Cambridge University Press.

Kishino, M., M. Takahashi, N. Okami, and S. Ichimure. 1985. Estimation of the spectral absorption coefficients of phytoplankton in the sea. Bulletin of Marine Sciences 37: 634-642.

Klonowski, W., P.R.C.S. Fearns, and M.J. Lynch. 2007. Retrieving key benthic cover types and bathymetry from hyperspectral imagery. Journal of Applied Remote Sensing 1: 1-21.

Kohler, D., P. Bissett, R.G. Steward, and C.O. Davis. 2004. A new approach for the radiometric calibration of spectral imaging systems. Optics Express 12(11): 2463-2477.

Kohler, D., Bissett, P., Steward, R. G., Kadiwala, M. and R. Banfield. 2006. Hyperspectral remote sensing of the coastal environment. Proceeding of Ocean Optics, XVIII, Montreal. 
Kurdziel, J.P., and S.S. Bell. 1992. Emergence and dispersal of phytaldwelling meiobenthic copepods seagrass. Journal of Experimental Marine Biology and Ecology 163: 43-64.

Kutser, T., I. Miller, and D. Jupp. 2006. Mapping coral reef benthic substrates using hyperspectral space-born images and spectral libraries. Estuarine Coastal and Shelf Science 70: 449-460.

Lee, Z.P., K.L. Carder, S.K. Hawes, R.G. Steward, T.G. Peacock, and C.O. Davis. 1994. Model for the interpretation of hyperspectral remote-sensing reflectance. Applied Optics 33(24): 5721-5732.

Lee, Z.P., K.L. Carder, C.D. Mobley, R.G. Stewart, and J.S. Patch. 1999. Hyperspectral remote sensing for shallow waters: 2. Deriving bottom depths and water properties by optimization. Applied Optics 38(18): 3831-3843.

Lee, Z.P., K.L. Carder, F.R. Chen, and T.G. Peakcock. 2001. Properties of the water column and bottom derived from Airborne Visible Infrared Imaging Spectrometer AVIRIS. Journal Geophysical Research 106(C6): 11639-11651.

Lesser, M.P., and C.D. Mobley. 2007. Bathymetry, water optical properties, and benthic classification of coral reefs using hyperspectral remote sensing imagery. Coral Reefs 26: 819-829. doi:10.1007/ s00338-007-0271-5.

Louchard, E.M., R.P. Reid, F.C. Stephens, C.O. Davis, R.A. Leathers, and T.V. Downes. 2003. Optical remote sensing of benthic habitats and bathymetry in coastal environments at Lee Stocking Island, Bahamas: A comparative spectra classification approach. Limnology and Oceanography 48(1): 511-521.

Mantoura, R. F. C., Jeffrey, S. W., Llewellyn, C. A., Claustre, H., Morales, C. E. and S. W. Wright. 1997. Comparison between spectrophotometric, fluorometric and HPLC methods for chlorophyll analysis fluorometric. In: Phytoplankton pigments in oceanography, eds. S. W. Jeffrey, et al., 361-380. Paris: UNESCO,

Marba, N., and C.M. Duarte. 1995. Coupling of seagrass (Cymodocea nodosa) patch dynamics to subaqueous dune migration. Journal of Ecology 83: 381-389.

Marbá, N., M. Holmer, E. Gacia, and C. Barron. 2006. Seagrass beds and coastal biogeochemistry. In Seagrasses: Biology, ecology and conservation, ed. A.W.D. Larkum, R. Orth, and C.M. Duarte. the Netherlands: Springer.

Maritorena, S., A. Morel, and B. Gentili. 1994. Diffuse reflectance of oceanic shallow waters: Influence of water depth and albedo. Limnology and Oceanography 39(7): 1689-1703.

Matarrese, R., Acquaro, M., Morea, A., Tijani, K. and Chiaradia. 2008. Application of remote sensing techniques for mapping Posidonia oceanica meadows. Proceedings of the IGARSS.

Mateo, M.A., J. Cebrian, K. Dunton, and T. Mutchler. 2006. Carbon flux in seagrass ecosystems. In Seagrasses: Biology, ecology and conservation, ed. A.W.D. Larkum, R. Orth, and C.M. Duarte. the Netherlands: Springer.

McNulty, J. K., Lindall, W. N. and Sykes, J. E., 1972. Cooperative Gulf of Mexico estuarine inventory and study, Florida: Phase I, area description. NOAA Technical Report NMFS CIRC-368, 126 p.

McPherson, M.L., V.J. Hill, R.C. Zimmerman, and H.M. Dierssen. 2011. The optical properties of Greater Florida Bay: Implications for seagrass abundance seagrass Florida. Estuaries and Coasts 34: 1150-1160. doi:10.1007/s12237-011-9411-9.

Meehan, A.J., R.J. Williams, and F.A. Watford. 2005. Detecting trends in seagrass abundance using aerial photograph interpretation: Problems arising with the evolution of mapping methods. Estuaries 28(3): 10.

Mitchell, B. G., Kahru, M., Wieland, J., Stramska, M., Mueller, J. L. and G. S. Fargion. 2002. Determination of spectral absorption coefficients of particles, dissolved material and phytoplankton for discrete water samples. In: Ocean optics protocols for satellite ocean color sensor validation, eds. G.S. Fargion, J.L. Mueller, C.R. McClain, 231-257. Greenbelt: NASA.
Mobley, C.D. 1994. Light and water: Radiative transfer in natural waters. San Diego: Academic.

Mobley, C.D., L.K. Sundman, C.O. Davis, J.H. Bowles, T.V. Downes, R.A. Leathers, M.J. Montes, P. Bissett, D. Kohler, R.P. Reid, E.M. Louchard, and A.C. Gleason. 2005. Interpretation of hyperspectral remote-sensing imagery by spectrum matching and look-up tables. Applied Optics 44(17): 3576-3592. doi:10.1364/AO.44.003576.

Morel, A., and J.L. Mueller. 2003. Normalized water-leaving radiance and remote sensing reflectance: Bidirectional reflectance and other factors, 32-59. Greenbelt: Goddard Space Flight Center.

Moriarty, D.J.W., R.L. Iverson, and P.C. Pollard. 1986. Exudation of organic carbon by the seagrass Halodule wrightii Aschers and its effect on bacterial growth in the sediment. Journal of Experimental Marine Biology and Ecology 96(2): 115-126.

Mumby, P.J., and A.J. Edwards. 2002. Mapping marine environments with IKONOS imagery: Enhanced spatial resolution can deliver greater thermatic accuracy. Remote Sensing of Environment 82: 9.

Mumby, P.J., E.P. Green, A.J. Edwards, and C.D. Clark. 1997. Measurement of seagrass standing crop using satellite and digital airborne remote sensing. Marine Ecology Progress Series 159: 5160.

Nelson, N.B., C.A. Carlson, and D. Stephenson. 2004. Production of chromophoric dissolved organic matter by Sargasso Sea microbes. Marine Chemistry 89: 273-287.

Orth, R.J., M.C. Harwell, E.M. Bailey, A. Bartholomew, J.T. Jawad, A.V. Lombana, K.A. Moore, J.M. Rhode, and H.E. Woods. 2000. A review of issues in seagrass seed dormancy and germination: Implications for conservation and restoration. Marine Ecology Progress Series 200: 277-288.

Orth, R., Wilcox, D. J., Nagey, L. S., Owens, A. L., Whiting, J. R. and A. K. Kenne. 2006. Distribution of submerged aquatic vegetation in Chesapeake Bay and Coastal Bays Virginia Institute of Marine Science. Special Scientific Report \#150.

Pasqualini, V., C. Pergent-Martini, G. Pergent, M. Agreil, G. Skoufas, L. Sourbes, and A. Tsirika. 2005. Use of SPOT 5 for mapping seagrasses: An application to Posidonia oceanica. Remote Sensing of Environment 94: 6.

Pegau, W. S., Zaneveld, R. V. and J. L. Mueller. 2002. Volume absorption coefficients: Instruments, characterization, field measurements and data analysis protocols. In: Ocean optics protocols for satellite ocean color sensor validation, revision 4 , volume $I V$, eds. J. L. Mueller, G. S. Fargion, C. R. McClain. Greenbelt: National Aeronautical and Space Administration.

Phinn, S.R., C. Roelfsema, A. Dekker, V. Brando, and J. Anstee. 2008. Mapping seagrass species, cover and biomass in shallow waters: An assessment of satellite multi-spectral and airborne hyper-spectral imaging systems in Moreton Bay (Australia). Remote Sensing of Environment 112: 3413-3425.

Pu, R., S.S. Bell, C. Meyer, L. Baggett, and Y. Zhao. 2012. Mapping and assessing seagrass along the western coast of Florida using Landsat TM and EO-1 ALI/Hyperion imagery. Estuarine, Coastal and Shelf Science 115: 234-245. doi:10.1016/j.ecss.2012.09.006.

Ralph, G.M., R.D. Seitz, R.J. Orth, K.E. Knick, and R.N. Lipcius. 2013. Broad-scale association between seagrass cover and juvenile blue crab density in Chesapeake Bay. Marine Ecology Progress Series 488: 51-63. doi:10.3354/meps10417.

Robbins, B.D. 1997. Quantifying temporal change in seagrass areal coverage: The use of GIS and low resolution aerial photography. Aquatic Botany 58(3-4): 259-267.

Robbins, B.D., and S.S. Bell. 2000. Dynamics of a subtidal seagrass landscape: Seasonal and annual change in relation to water depth. Ecology 81(5): 1193-1205.

Rose, C.D., W.C. Sharp, W.J. Kenworthy, J.H. Hunt, W.G. Lyons, E.J. Prager, J.F. Valentine, M.O. Hall, P.E. Whitfield, and J.W. Fourqurean. 1999. Overgrazing of a large seagrass bed by the sea 
urchin Lytechinus variegatus in outer Florida Bay. Marine Ecology Progress Series 190: 212-222.

Sagawaa, T., E. Boisniera, T. Komatsu, K.B. Mustaphab, A. Hattourb, N. Kosakac, and S. Miyazakic. 2010. Using bottom surface reflectance to map coastal marine areas: A new application method for Lyzenga's model. International Journal of Remote Sensing 31(12): 3051-3064.

Savastano, K.J., K.H. Faller, and R.L. Iverson. 1984. Estimating vegetation coverage in St. Joseph Bay, Florida with an airborne multispectral scanner. Photogrammetric Engineering and Remote Sensing 50(8): 1159-1170.

Sfriso, A., and P.F. Ghetti. 1998. Seasonal variation in biomass, morphometric parameters and production of seagrasses in the lagoon of Venice. Aquatic Botany 61: 207-223.

Short, F.T., and S. Wyllie-Echeverria. 1996. Natural and human-induced disturbance of seagrasses. Environmental Conservation 23(1): 17-27.

Silva, T.S.F., M.P.F. Costa, J.M. Melack, and E.M.L.M. Novo. 2008. Remote sensing of aquatic vegetation: Theory and applications. Environmental Monitoring and Assessment 140: 131-145.

Stewart, R.A., and D.S. Gorsline. 1962. Recent sedimentary history of St. Joseph Bay, Florida. Sedimentology 1: 256-286.

Thorhaug, A., A.D. Richardson, and G.P. Berlyn. 2007. Spectral reflectance of the seagrasses: Thalassia testudinum, Halodule wrightii, Syringodium filiforme and five marine algae. International Journal of Remote Sensing 28(7): 1487-1501.

Vahtmae, E., T. Kutser, G. Martin, and J. Kotta. 2006. Feasibility of hyperspectral remote sensing for mapping benthic macroalgal cover in turbid coastal waters - a Baltic Sea case study. Remote Sensing of Environment 101: 342-351. van Tussenbroek, B.I. 1998. Above- and below-ground biomass and production by Thalassia tesudinum in a tropical reef. Aquatic Botany 61: 69-82.

Warren, M.A., R.S. Gregory, B.J. Laurel, and P.V.R. Snelgrove. 2010. Increasing density of juvenile Atlantic (Gadus morhua) and Greenland cod (G. ogac) in association with spatial expansion and recovery of eelgrass (Zostera marina) in a coastal nursery habitat. Journal of Experimental Marine Biology and Ecology 394(1-2): $154-160$.

Waycott, M., C.M. Duarte, T.J.B. Carruthers, R. Orth, W.C. Dennison, S. Olyarnik, A. Calladine, J.W. Fourgurean, K.L. Heck, A.R. Hughes, G.A. Kendrick, W.J. Kenworthy, F.T. Short, and S.L. Williams. 2009. Accelerating loss of seagrasses across the globe threatens coastal ecosystems. Proceedings of the National Academy of Sciences 106(30): 5. doi:10.1073/pnas.0905620106.

Wetherell, V. 1997. St. Joseph Bay aquatic preserve management plan. Washington, DC: U. S. Government Printing Office.

With, K.A., and T.O. Crist. 1995. Critical thresholds in species responses to landscape structure. Ecology 76: 2446-2459.

Yangab, C., D. Yanga, W. Caoa, J. Zhaoab, G. Wanga, Z. Suna, Z. Xuab, and M.S.R. Kumarb. 2010. Analysis of seagrass reflectivity by using a water column correction algorithm. International Journal of Remote Sensing 31(17-18): 4595-4608.

Zieman, J.C., J.W. Fourgurean, and R. Iverson. 1989. Distribution, abundance and productivity of seagrasses and macroalgae in Florida Bay. Bulletin of Marine Sciences 44(1): 292-311.

Zimmerman, R.C. 2003. A biooptical model of irradiance distribution and photosynthesis in seagrass canopies. Limnology and Oceanography 48(1, part 2): 568-585. 